\title{
SOCIOLOGÍA DE LA MODERNIZACIÓN DEL ESTADO Y RELACIONES LABORALES EN CHILE. UN ESTUDIO EXPLORATORIO SOBRE MODELOS DE SERVICIO PÚBLICO
}

\author{
Alfonso Arrau C. \\ Proyecto FONDECYT N ${ }^{\circ} 1940412,1996$.
}

\section{INTRODUCCION.}

"La democracia hoy debe basarse en la creación de nuevos espacios públicos que no sean estatales y nuevos lugares privados que no sean mercantiles".

John Keane, Public Life \& Late Capitalism.

Desde hace siglos en Occidente se define en términos sociológicos al Estado como una institución moderna, identificándose ésta con la formación del Estado-nación y secularizadas maneras de legitimar la autoridad centralizada'. Estado y Nación son dos aspectos del mundo social moderno que se suponen recíprocamente, haciendo uno inteligible al otro. De aquí que resulta paradojal la necesidad de modernizar al Estado moderno. Esta necesidad se articula hoy a megatendencias mundiales ligadas a la crisis de un particular arreglo institucional, el Estado de Bienestar o Benefactor, que se generalizara con vigor a partir de la posguerra.

Michel Crozier, a partir de un estudio comparativo de los casos de Estados Unidos, Japón y Suecia, concluye que la lógica de la modernización responde a cinco desafíos fundamentales:

i) La sociedad industrial clásica, tal como la conocemos, está en vías de desaparición. Sus modelos de razonamiento cuantitativos están agotados. El sistema administrativo, formas de gobierno, de decidir, de intervención y control del Estado que estaban asociados a ella deben ser profundamente renovados para adaptarse a un nuevo mundo.

ii) La desviación financiera puesta en movimiento por la acumulación de los compromisos del Estado es insostenible en la actualidad, en la medida que el envejecimiento de las poblaciones la agravará más en los quince o veinte años próximos.

iii) La proliferación de reglamentos que se comprueba en todas partes no sólo es ineficaz sino paralizante para la economía y la sociedad. Corre el riesgo de reprimir cada vez más la capacidad de innovación indispensable para mantener el desarrollo.

iv) La población espera desde ahora prestaciones cualitativas y una participación más activa en la administración de las actividades colectivas.

v) Estos cambios ponen en duda un modelo administrativo y gubernamental en lo sucesivo inadaptado. La reforma de este modelo es uno de los escollos, si no el escollo de la adaptación de la sociedad al mundo del siglo XXI.

De estas tendencias pareciera que la que ejerce mayor gravitación son los compromisos del Estado, pues como indica el mismo autor el impulso modernizador se reduce cuando se avizora algún equilibrio en las finanzas públicas. Chile no es una excepción al respecto y el tema de la modernización del Estado surge directamente asociado a la aguda crisis de la deuda externa y el

\footnotetext{
' Una extensa discusión sobre la significación del Estado-nación, ver R.H.S. Crossman, "Biografía del Estado Moderno", F.C.E 1996.

"Michel Crozier, "Cómo reformar al Estado". F.C.E. 1992, pág. 121.
} 
déficit fiscal de los años 80, acompañado con la reestructuración económica impulsada por el régimen militar en la misma década y la ofensiva ideológica del neo-liberalismo. Para esta última tendencia la modernización estatal aparece como una condición de consolidación de la modernización económica del régimen autoritario. (1973-1990).

En la Sociología hoy y particularmente en Chile el tema de la modernización del Estado representa un giro intelectual de data reciente. En efecto, durante los años del régimen militar, no obstarte su ostracismo y fragmentación discipinaria, la sociología estuvo centrada en los esfuerzos teóricos y prácticos de la recuperación democrática. El tema de la transición estuvo en el centro de la reflexión e investigación sociológica. Estudios sectoriales y referidos a actores sociales dieron origen a una expresiva literatura al respecto. El interés por la modernización o reforma del Estado se inaugura en esta disciplina con el restablecimiento de la democracia (1990) ${ }^{3}$.

Por ahora se trata más de una agenda de trabajo e investigación que de logros o resultados teórico-empíricos. Esta agenda es amplia y heterogénea y levanta numerosas preguntas críticas acerca de la modernización. La categoría modernización del Estado habitualmente denota el sesgo economicista de una activa política de privatización de patrimonio público y reducción del tamaño de su aparato administrativo. Por esta razón, en la literatura sociológica es frecuente el uso de la categoría reforma en reemplazo a modernización.

Este documento pretende abrir el debate sobre el tema arrancando de una investigación exploratoria recientemente concluida que constituye el primer intento por desarrollar desde la Sociología una aproximación teórico-empírica sobre la Modernización del Estado ${ }^{4}$. Dicha investigación privilegió la relación Estado-Sociedad Civil con vistas a contextualizar los problemas de reforma situándolos en el marco de una sociedad sometida a profundas transformaciones. Se planteó en términos críticos a toda visión tecnocrática de la modernización, "la que se refiere esencialmente a las soluciones y no a los problemas y donde el análisis es acaparado por los expertos", otorgando espacio "al decir y al sentir" de funcionarios del sector público. Partiendo de supuestos relativos al proyecto de modernización del régimen autoritario ${ }^{6} \mathrm{y}$ con el despliegue de paradigmas conceptuales inició la exploración de modelos alternativos de servicio público. En el diseño de la investigación no se presume que estos modelos sean asumidos consciente y coherentemente en las acciones cotidianas por los funcionarios públicos. Se trata de universos simbólicos diferentes entre los cuales puede darse mayor o menor correspondencias.

La investigación que se comenta es un primer escrutinio de los términos de la discusión acerca de la modernización en el marco del Estado en Chile. El ámbito del proyecto fue las relaciones laborales, desagregándolas conforme a distintas concepciones del rol del Estado en esas relaciones. El foco de atención pertinente es la detección y análisis de "modelos de servicio público". pues es alií donde se cristalizan de un modo más o menos coherente la percepción que los distintos actores estatales tienen de su guión o libreto en un escenario operativo y sus consecuencias potenciales en un proceso de modernización.

En la investigación se utilizaron diferentes fuentes de información, documentos oficiales de gobierno, entrevistas en profundidad a representantes de la inteligentzia pública y grupos de discusión formados por funcionarios de la Dirección General del Trabajo y Previsión Social. Por tratarse de una aproximación exploratoria y no distributiva, la investigación no pretende representar 'el decir y el sentir' del conjunto de los trabajadores estatales ni de los funcionarios de la institución.

Alfonso Arrau, "Modernización del Estado o estado de la modernización?". Ponencia presentada al V Congreso Chileno de Sociología, Concepción 1994.

"Alfonso Arrau, "Modernización del Estado y Relaciones Laborales en Chile. Proyecto Fondecyt N" 1940412. Ver Informe de Investigación, 1996.

"Michel Crozier, op. cit , pág. 15.

"Alfonso Arrau, "Modemización y Redemocratización en Chile". en Revista de Sociología, N 6-7, 1992. 


\section{LAS RELACIONES LABORALES EN CHILE.}

En el documento denominado 'Modernización y Redemocratización en Chile' se sostiene que el proyecto de hegemonía del régimen militar constituyó 'un amplio programa de resocialización total de la población vis-a-vis la institucionalización de la motivación y el éxito económico. Se erigió al mercado como ente regulador de la vida social, construyendo el escenario figurado de formación y desarrollo del 'homo economicus' o abstracción neoclásica del actor racional?.

El programa de la referencia implicó "un cambio fundamental en la relación salarial... que se tradujo en una (fragmentación y) devaluación social y económica del conjunto de la clase trabajadora". Este hecho estructural.no ha impedido que desde el establecimiento del gobierno democrático se haya generado un diálogo social que involucra a gobierno, trabajadores y empresarios y cuyo producto más relevante es la suscripción de sucesivos acuerdos marco. Esta capacidad de diálogo y acuerdos esta en correspondencia con la compleja ingeniería política desplegada en la transición a la democracia. Pero también está en correspondencia con los procesos de transformación colaterales ocurridos en la empresa, la economía ๒ la sociedad chilenas.

El principal antecedente de estas transformaciones es la apertura radical de la economía chilena al comercio internacional bajo el principio de las ventajas comparativas y dentro del marco de la globalización capitalista. En lo local significó el tránsito de unāeconomía orientada por la estrategia keynesiana de la demanda solvente a los supuestos neoclásicos de la escasez y, por tanto, la competencia.

Con la cancelación de la estrategia keynesiana, que en su momento hiciera suya la CEPAL para la región, se canceló también el pacto político que explicaba la cooperación y zonflicto en la democracia capitalista y un antecedente clave del Estado de Bienestar. En :́rminos de Adam Przeworski, el keynesianismo constituyó "una justificación a los partidos zolíticos que representaban a los trabajadores para montar sus oficinas en la sociedad capiSalista"." Este autor entiende la democracia capitalista como compromiso de clases. La comzinación de la propiedad privada de los medios de producción y el sufragio universal implisa que la lógica de la acumulación de capital no sea lógica exclusiva de actores privados. Si aquellos que no poseen el capital han de consentir voluntariamente la propiedad privada de os medios de producción, han de tener un grado de certeza razonable que sus condiciones materiales van a mejorar en el futuro como resultado de la actual apropiación de beneficios "zalizada por los capitalistas - de la cual parte va a la inversión. Cualquier compromiso de zlases ha de tener, por tanto, al menos dos aspectos: uno, tocante a la redistribución de la - znta y, el otro, tocante a la inversión. Este compromiso es básicamente institucional: los rabajadores consienten la institución de la propiedad privada a cambio que los capitalistas zonsientan instituciones políticas a través de las cuales otros grupos puedan procesar eficazmente sus demandas.

Como certeramente apuntan Campero, Flisfisch y otros ${ }^{10}$, bajo este compromiso, en el

Arrau, op cit. 1992

Cecilia Montero, 'Crisis del Empleo y Relaciones Sociales'. en Francisco Zapata. compilador, 'Clases Sociales y Acción Obrera

Chile'. El Colegio de México 1986, pág. 60.

Adam Przeworski. 'Capitalismo y Social Democracia, Alianza Liniversidad 1990, pág. 235.

Guillermo Campero, Angel Flisfisch, Eugenio Tironi. Víctrr Tokman. 'Los Actores Sociales en el Nuevo Orden Laboral', Ed. men OIT 1993. 
caso chileno las variables empleo, condiciones de trabajo y salarios adquirieron un carácter eminentemente político e independiente de la "legalidad económica". La política de pleno empleo, de mejora y compensaciones sectoriales en las condiciones de trabajo y aumento de salarios eran negociadas con alta presencia protectora de los gobiernos en favor de los trabajadores. Estos objetivos eran concebidos como patrones universales a los que debía adaptarse cualquier regulación económica y la acción sindical podía proponerse empujar las políticas gubernamentales en esa dirección.

La reconversión impulsada por el régimen militar es responsable de la emergencia de una nueva matriz en las relaciones de trabajo. Tema complejo que implica numerosas variables y sus interrelaciones. Sólo con propósitos de problematización se señalan los siguientes aspectos de la nueva matriz.

\section{Mercado formal de trabajo.}

En estos últimos años cabe verificar cambios importantes en la composición y la calidad del empleo. En primer lugar, la tasa de crecimiento del empleo agrícola declina hasta hacerse negativa hacia 1989. En segundo lugar, en el mismo sector agrícola desde 1992 el trabajo informal se desacelera considerablemente. En tercer lugar, desde 1991 se asiste a un aumento consistente del empleo en el sector no agrícola, tanto formal como informal, llegando a tasas promedio de 6,3\%. para 1993. Finalmente, la productividad media de la ocupación ha tenido un crecimiento de 3,1\% por año entre 1990-1993.

Después de un período (1986-1989) que corresponde a una etapa de recuperación económica, el mercado laboral se vio afectado por el proceso de ajuste antiinflacionario iniciado en 1990, recuperando sus tasas de crecimiento en torno al 4,6\% hacia 1992. La desocupación se ha mantenido en los últimos años a tasas estimadas de pleno empleo $(4,4$ a 4,5\%).

Si bien existen bajos índices de cesantía, en algunas instancias se constata rotación de la fuerza de trabajo, en especial en el segmento de profesionales y personal altamente calificado. Esa movilidad horizontal o intersectorial que parece ser relativamente nueva en la economía chilena esta reforzando la importancia de temas como los mecanismos de estabilización de ingresos o seguro de desempleo y expedientes mas efectivos de capacitación. (Mejías) ${ }^{11}$.

En referencia al mercado formal de trabajo, el laboralista Alfredo Valdés sostiene que el Derecho del Trabajo está quedando progresivamente obsoleto por cuanto "aumentan día a día el contingente de personas que laboran sin su protección, que las llamadas formas "atípicas" de contratación aumentan sustancialmente en desmedro del trabajo formal, reglado, permanente y subordinado" 12 . Los desfases normativos están produciendo connivencia entre empresarios y trabajadores por informalizar determinadas situaciones laborales. Estas observaciones son confirmadas por la experiencia de la Dirección del Trabajo. A este respecto, existe un artículo que faculta a este servicio para autorizar jornadas de trabajo excep-

\footnotetext{
"Entrevista Sergio Mejías, Subdirector DdT.

${ }^{12}$ Alfredo Valdés. 'De las relaciones individuales de trabajo', en Walker y Arrau. Ed. 'Las relaciones de trabajo en el Chile de hoy'. Universidad de Chile 1993, pág. 217.

${ }^{13}$ Entrevista ref.
} 
cionales; sin embargo, la cantidad de solicitudes es de tal magnitud que hoy lo excepcional ha pasado a constituir la norma. En sentido contrario, muchos esfuerzos por incorporar sectores a la fuerza de trabajo se complican con la actual estructura de la jornada laboral. Asimismo, normas protectoras como las relativas al fuero materno en la práctica ha significado muchas veces la exclusión de la mujer de la fuerza de trabajo. Cómo formalizar el mercado de trabajo en ambientes de creciente informalidad parece constituir el principal problema. Constituye un desafío tanto a las nuevas formas del Derecho como a las relaciones directas entre los actores sociales.

En ausencia de una ley de organización del mercado de trabajo se manejan indistintamente las categorías de desrregulación y flexibilidad aunque éstas no denoten lo mismo. La tesrregulación a veces adquiere un sentido más específico como desreglamentación procu:ando dar más autonomía a los actores sociales. Pero ligando ambos términos, Mejías sostiene que "uno desregula cuando desprotege en tanto que flexibiliza cuando cambia las fórmuas de protección" "13. En el derecho del trabajo existen distintas fórmulas de protección: la :utela administrativa, la jurisdiccional, la normativa y la autotutela. Si se elimina la tutela normativa y se reducen los rangos de protección que la ley ofrece, sin introducir alguna otra $\therefore$ ternativa de protección, no se está flexibilizando sino que desrregulando. Por el contrario. i se reducen los rangos de tutela normativa pero se favorece por ejemplo la formación de rganizaciones sindicales más fuertes, se está flexibilizando con la protección de la autotutela. E tos temas surgen asociados a Ia dinámica de la economía y ponen en evidencia importanzs dificultades a las regulaciones puramente jurídico-normativas. Según Campero "la am- iación de la negociación colectiva tendería a fortalecer la formalización del mercado de abajo" 14 .

\section{Capacitación profesional.}

Con el dinamismo de la economía, medido en términos de sectores que crecen y se randen, con otros que se contraen y desaparecen, con la velocidad de difusión del conociento científico-tecnológico y debido a las demandas de mejora en la calidad de los emsos, la capacitación profesional se está transformando en un eje articulador central. La - :stión que se plantea aquí es la de conseguir una fuerza de trabajo en permanente reciclaje nder a la calificación permanente de los recursos humanos en las organizaciones. En e. "la capacidad de reciclaje está tomando en promedio entre doce y quince años en :o que en los países asiáticos está tomando sólo cuatro años" (Mejías) ${ }^{15}$. Paradojalmente, le es uno de los pocos países donde sobra plata para capacitación por cuanto no se está zando plenamente la franquicia tributaria. En la PYME, por ejemplo, un $1 \%$ de la plani¿ sueldos permite hacer muy poco en capacitación. Además, debido a la débil estructura a mediana y pequeña empresa existe el temor fundado entre los empresarios que la * :citación contribuye a crear o fortalecer finalmente a la competencia. Así, de los fondos capacitación "se utiliza más o menos un 35\%: de éste, un $80 \%$ se utiliza en la gran zresa; y de ese $80 \%$, más de un $50 \%$ se utiliza en los cuadros gerenciales" (Mejías) ${ }^{16}$. 
Con todo, a pesar del crecimiento en las tasas de capacitación, en el año 1994 el número de trabajadores capacitados representó sólo el 10,4\% de la fuerza de trabajo como se puede apreciar en la tabla $\mathrm{N}^{\circ} 1$.

\section{Tabla $N^{o} 1$. \\ Trabajadores capacitados vía SENCE franquicia tributaria.}

$\begin{array}{lcc}\text { Año } & \text { Trabajadores capacitados } & \text { \% fuerza trabajo } \\ 1990 & 199.604 \text { personas } & 6,1 \% \\ 1991 & 232.728 \text { personas } & 6,9 \% \\ 1992 & 283.635 \text { personas } & 8,0 \% \\ 1993 & 326.635 \text { personas } & 8,7 \% \\ 1994 & 385.014 \text { personas } & 10,4 \%\end{array}$

Fuente: Julio Valladares, Director Nacional del SENCE.

Tabla $N^{\circ} 2$.

Inversión pública y privada en capacitación en \$ millones

$\begin{array}{lccc}\text { Año } & \text { Aporte público } & \text { Aporte empresas } & \text { Totales } \\ 1990 & 10.016 & 4.815 & 14.831 \\ 1991 & 12.165 & 5.214 & 17.379 \\ 1992 & 13.617 & 6.405 & 20.022 \\ 1993 & 16.309 & 7.101 & 23.410 \\ 1994 & 20.218 & 7.478 & 27.696\end{array}$

Fuente: Julio Valladares, Director Nacional del SENCE.

Estas cifras están bastante distantes de lo realizado por países que llegan a tasas del $20 \%$ de su fuerza laboral. Además de su significación universal, el tema de la capacitación se hace particularmente crítico en relación a los fenómenos de reconversión productiva, cuestión que requiere mecanismos estables y flexibles de capacitación por su recurrencia en la nueva matriz.

\section{Productividad.}

Los aumentos de productividad constituyen el gran desafío en economías con alto nivel de competitividad local e internacional. El tema de la productividad es el más crítico en la modernización de las relaciones laborales, principalmente por su triangulación con la capacitación profesional y las remuneraciones.

El comportamiento de las remuneraciones está influido por las negociaciones que se realizan en el sector privado, por las políticas de reajuste del sector público y del salario mínimo. De esta combinación resulta el nivel general de salarios. El crecimiento promedio de las remuneraciones reales entre 1990-93 fue de un 3,7\%, siendo el crecimiento del Producto Interno Bruto en el mismo período de un 10,4\%. La participación de los salarios en el PIB en el año 1993 llegó al 39\%. Si bien esta última cifra constituye una participación 
mayor en los últimos años, está muy lejos de la participación histórica de los salarios que hacia 1970 bordeaba el 50\% del Producto.

Durante el régimen militar las remuneraciones de la Administración Pública experimentaron gran inestabilidad, pues constituyeron uno de los principales factores de ajuste de las finanzas públicas. Entre 1979-1990 los sueldos bases tuvieron un deterioro real del $47 \%$. Esta caída fue más significativa en algunos sectores, los servicios traspasados a las municipalidades, salud, educación, obras públicas, vivienda y Tesorerías, Desde el restablecimiento de la democracia, se han notado algunas mejoras. Por de pronto, se ha aumentado entre 1989-93 el gasto en personal pasando de un 20\% a un 22\% del gasto corriente del sector público. Este incremento, además de reducir déficit en servicios básicos que explica un crecimiento del empleo a una tasa anual del $2,7 \%$, ha permitido que el conjunto de las remuneraciones del sector público creciera en cerca de un $30 \%$ real, duplicando de paso el crecimiento real del índice general de remuneraciones en el mismo período. El sector que experimentó un mayor crecimiento en sus remuneraciones fue el sector salud, en tanto que el más rezagado en esta progresión fueron los funcionarios municipales ${ }^{17}$.

Algunos acuerdos en el sector público han intentado establecer una directa vinculación əntre mejoramiento de remuneraciones y productividad. Así, por ejemplo, con el Colegio de Profesores se acordó a partir de 1996 una asignación destinada a premiar a los profesores pertenecientes al $25 \%$ de escuelas subvencionadas de mejor rendimiento en cada región. Por otra parte, en 1994, al momento de discutir el reajuste de remuneraciones del sector público, con la CUT se concordó como criterios relevantes: la inflación futura, un incremento por concepto de productividad y un factor adicional que permita ir cerrando la brecha entre el sector público y el privado.

Con respecto a la capacitación profesional también se han formulado algunas políticas te asociación con las remuneraciones y la productividad. El acuerdo salarial de 1994, por jemplo, incorpora un compromiso por mejorar la cantidad y calidad de la capacitación que :e efectúa en el sector público y la aplicación, a partir de 1996, de un incentivo por desem?eño funcionario.

\section{Actores sociales.}

Sería congruente en este contexto leer las relaciones en el mundo del trabajo en clave homo economicus' y, en efecto, con ese ideario está estructurada la Constitución Política de 980 y la actual legislación laboral. Consagra dos conceptos fundamentales: la propiedad rrivada y la libertad de trabajo. El espacio por excelencia de la cooperación social es la empresa. El empresariado pasa a ser innovador y líder de la producción y nada debe coartar - u plena potestad contractual en la empresa en materia de inversión, gestión, administración $\because$ control. Los trabajadores deben maximizar sus oportunidades de empleo productivo eviando cualquier expediente que bloquee la movilidad y libertad de trabajo. Se establece la ibre afiliación sindical y la negociación a nivel de empresa, etc. Sin embargo cabe matizar zstas observaciones considerando algunas externalidades a la figura dominante.

Comité Interministerial, 'Modernización de la Gestión Pública, 1994. 
Según Campero ${ }^{18}$, en el marco de las relaciones vigentes las organizaciones sindicales hicieron un aporte sustantivo al proceso de transición, haciendo un sacrificio de demandas. Pero al mismo tiempo la representación sindical -la CUT en especial- logró resultados políticos importantes, por su presencia nacional como actor reconocido y legitimado por el gobierno y el empresariado. La CUT sería hoy un actor dirigente de la política nacional, lo que no es siempre adecuadamente reconocido por el propio actor sindical y hace que la imagen subjetiva transmitida sea más pesimista que optimista. Además, a pesar de los sacrificios anotados, en términos de empleo e ingresos la situación global no fue desfavorable para los trabajadores, si bien con desigualdades evidentes inter e intra sectores laborales.

Desde 1994 se vive la activación de demandas contenidas, lo que ocurre no sólo entre sindicalistas sino también entre otros sectores. Para el mismo Campero, el punto es hasta dónde tal activación adquiere un carácter corporativista, particularista, o hasta dónde se combina la demanda privada con intereses generales de la transición, que no está terminada. El sindicalismo está naturalmente oscilando entre una y otra orientación. debido a que enfrenta la activación de demandas y, al mismo tiempo, tiene conciencia de su papel en la transición no terminada. A la representación sindical habría que ponerle "valor agregado" de propuestas y alternativas, establecer una capacidad técnica superior, desafío aún pendiente para el sindicalismo.

Siguiendo con la misma entrevista, Campero sostiene que en el campo del empresariado el problema hoy es su visión cortoplacista en materia de relaciones laborales y su ideologismo extremo. Este sector no ha logrado modernizarse en este tema lo suficiente y tiene más temores que ideas nuevas al respecto. Pese al rol central que se le asigna y al papel estratégico que está jugando, no admite la modernización democrática de las relaciones laborales como un componente de su propia capacidad de potenciarse en la competencia internacional. Mediadas por el proyecto de reforma de las leyes laborales, las turbulencias de estos tiempos vendrán más de este lado que del sindical.

Basta para confirmar la reciente afirmación la frontal actitud de rechazo asumida por la CPC a las reformas laborales enviadas por el gobierno al parlamento. En palabras de Walter Riesco, titular dé la comisión laboral de la Confederación, "existe unanimidad entre las ramas de la confederación en cuanto a que el contenido del proyecto de ley en su totalidad es absolutamente inconveniente" ${ }^{\prime 9}$. Los principales tópicos de oposición al proyecto de ley están referidos al alcance de la información que los empresarios deberían facilitar a los trabajadores en la negociación colectiva que conduciría en palabras de Riesco "a una suerte de coadministración", a la ampliación del fuero sindical, al castigo a los empleadores por conductas antisindicales y las restricciones a la contratación de reemplazantes en caso de huelgas. Con estos expedientes se estaría "atentando contra el derecho de propiedad" y el Proyecto de Reforma sería inconstitucional.

En suma, el modelo en curso hace que las relaciones de trabajo estén más radicadas en la empresa, tecnificadas y económicas. Esto politiza de otra forma a las relaciones laborales: hace a los actores sociales tipo CUT o CPC corresponsables de pactar las reglas de estabilidad global del sistema, pero no les otorga la capacidad para intervenir en la fijación de las condiciones de trabajo y empleo a nivel micro económico. Hoy, la capacidad mayor de

\footnotetext{
18 Entrevista.

${ }^{19}$ Walter Riesco, 'Reformas Laborales: lo que preocupa a los empresarios' Entrevista Diario 'La Epoca" Febrero 4, 1995, Cpo. B.
} 
ejercer poder social estaría en la empresa y no en los niveles sectoriales. Sobre ésto hay una gran discusión, todavía muy doctrinal e influida naturalmente por la larga experiencia histórica de un sindicalismo forjado en todo el mundo bajo las reglas del taylorismo y el fordismo y en el marco de una opción económica keynesiana.

En otro contexto y también con externalidad a la lógica del homo economicus, cabe Jestacar la emergencia de organizaciones económicas populares u organizaciones centradas en el trabajo y de baja productividad, que se han extendido y aparentemente consolidado con la crisis estructural. Su espectro es heterogéneo y va desde las organizaciones puramente asistenciales hasta las productivas como talleres artesanales y micro empresas. Estas últimas :evisten mayor interés por cuanto su expansión coincide con los momentos de mayor crecimiento económico. Más allá de la discusión ideológica sobre el alcance y significado de estas organizaciones ${ }^{20}$, representan una ambivalencia en el contexto actual: por una parte, se distinguen por una racionalidad económica propia, distinta a la rentabilidad de mercado; y por otra, representan una demanda al Estado en términos de equidad. Pero con la condición diferencial que si en el marco de una economía protegida y un Estado de Bienestar se pensaa que los sectores de nula o baja productividad eran condición de reproducción del sistema zconómico y objeto de atención preferencial del Estado, hoy se da una dinámica cuya disyuniva es adaptación o exclusión. Los sectores de nula o baja productividad pierden interés en a nueva matriz incluso como "objetos de explotación" 21 . Estas tendencias se harán probaวlemente más extendidas y agudas con la consolidación del proceso de apertura de la economía chilena, acuerdos de libre comercio mediante.

Los problemas de articulación que reportaría la nueva matriz hace más fragmentaria y compleja una estructura históricamente heterogénea y pone en evidencia nuevas contradic:iones tanto a nivel global como si se confrontan empresas y sectores económicos. En efec$\checkmark$. como se aprecia en la tabla $N^{\circ} 3$ el mapa de la estructura productiva del país muestra hoy Hertes contrastes si estimamos la distribución de la población económicamente activa y - olúmenes de ventas según tamaño de las empresas.

Tabla $N^{\circ} 3$.

Distribución PEA y Volúmenes de ventas según tamaño empresas.

\section{Tamaño empresa}

Grandes empresas

Pequeñas y medianas PYME

Micro-empresas cuasi-informales

PEA estimada: 4.800 .000 personas

Población
$20,2 \%$
$36,5 \%$
$43,3 \%$

\section{Volumen ventas}

$75,25 \%$

$19,80 \%$

$4,95 \%$

Fuente: Mario Marcel, Cinseyt, 1994.

De aquí que a futuro cabe hacer algunas preguntas. ¿En un proceso de globalización y *ansnacionalización capitalista como el vigente actualmente, con énfasis en la oferta, la roductividad y la competitividad, es empíricamente razonable seguir visualizando a los

\footnotetext{
Ver en especial. Luis Razetto, 'Centralidad del trabajo y economía de la solidaridad', en Osorio y Weinstein Ed. 'El corazón del - $=$ iris'.

Fernando Henrique Cardoso, 'Conferencia CLACSO', Chile 1991.
} 
trabajadores y al sindicalismo como centrales a los procesos de cooperación y conflicto social o se está haciendo irreversible la separación entre política y economía y consolidándose el 'homo economicus' como figura clave de la modernización? En otros términos, bajo los parámetros señalados ¿cabe reconstruir algún compromiso institucional análogo al que se dio en el Estado de Bienestar? ¿Los criterios de capacitación profesional y productividad ligadas al ingreso y la renta serían pertinentes? ¿Qué criterios se pueden inducir desde el Estado?

Estas preguntas están abiertas porque el cambio en la economía no ha ido de la mano con cambios en la relación y legislación laborales. Cortázar ${ }^{22}$ sostiene que esta asincronía hace que hoy se planteen en lo principal dos posiciones irreconciliables: por una parte, la visión neoliberal, que postula un mercado omnipresente y autorregulador y que pasa por sobre los antiguos dominios del Estado; por la otra, una postura restauradora que quiere reconstituir la participación negociadora del Estado en materias laborales, haciendo omisión de la nueva situación de la economía mundial. En contra de ambas posiciones, este autor postula una estrategia de canalización y regulación de demandas y conflictos. Para ser exitosa requiere de dos condiciones: i) desplegar una estrategia de negociación que implica un grado significativo de participación del conjunto de los actores organizados; ii) que los desenlaces de la negociación incluyan incentivos para que los actores acepten y cumplan las decisiones acordadas.

En el entendido que el escenario descrito sea un marco de problematización o hipótesis de trabajo plausible cabe formular las siguientes preguntas desde la modernización del Estado. ¿Corresponde al Estado, en especial a su rama ejecutiva y legislativa propender en su proyecto modernizador a la institucionalización de un sistema de relaciones laborales? En caso afirmativo, ¿qué aspectos o dimensiones son prioritarias? ¿Cuál es el rol del Estado en ese proceso de institucionalización? ¿Qué criterios comunes y diferenciales ameritan los distintos sectores y en especial el contraste entre lo estatal y lo privado?

Se han formulado dos bloques de preguntas que difícilmente pueden tener respuestas directas pero que sirven como guía en la discusión de los paradigmas y de las otras fuentes de investigación. El primer bloque apunta a la esfera de lo público en términos de la probabilidad de un acuerdo o pacto que definiría a futuro la cooperación y el conflicto social. El segundo bloque se refiere a la capacidad del Estado de inducir procesos de institucionalización en la relación de los actores que participan en el mundo del trabajo, incluyendo las dimensiones estatal y privada.

Un área estratégica para iniciar la exploración en torno a estas preguntas es el área de la administración del trabajo, la cual se entiende como las actividades de la administración pública en materia de política nacional del trabajo y comprende a las organizaciones que participan en estas actividades, las cuales conforman el sistema de administración. La institución que hace de cabeza en este sistema es la Dirección General del Trabajo dependiente del Ministerio del Trabajo y Previsión Social. Allí se centró el esfuerzo exploratorio y empírico de la investigación.

\footnotetext{
${ }^{22}$ René Cortázar, 'Política Laboral en Chile democrático'
} 


\section{PARADIGMAS DE MODERNIZACION DEL ESTADO}

Pareciera presuntuoso en una discusión sociológica apelar al criterio de paradigma. Para muchos la sociología es una disciplina pre-paradigmática, pues no habría logrado la condición señalada por Thomas S. Kuhn de "ciencia normal" "3, o cuerpo sistemático de conocimientos que descansa en un conjunto de supuestos compartidos por una comunidad disciplinaria. Lo más próximo a esta condición estuvo asociado en la post guerra al ideal comtiano de una "ciencia natural de la sociedad" representada por el funcionalismo positivista.

El concepto de ciencia y en especial de ciencia social ha sufrido profundas transformaciones, muchas de ellas con cargo precisamente a la visión positivista, en las que los aportes de la historia y la sociología de la ciencia no han sido de rango menor. Hoy, er, las ciencias sociales se acepta el pluralismo epistemológico y la competencia entre paradigmas. Más aún, se valora esta condición como estímulo para la discusión e investigación científica. Por ello es teórica y metodológicamente pertinente interrogar a distintas tradiciones intelectuales acerca del "Estado de la cuestión". La entrada por la vía de los paradigmas permite poner discursivamente los aprontes que se debaten en el campo de las ciencias sociales en relación a una determinada temática.

Por paradigma se entiende, siguiendo a Kuhn, ideas compartidas por una comunidad científica que definen los problemas y modos de indagación aceptados por esa comunidad para abordar un área particular de conocimientos. Los paradigmas proveen supuestos, proposiciones y estrategias conceptuales que intentan crear o proponer algún orden. No son propiamente hablando descriptores de hechos en sentido positivista, sino de eventos o eventualidades, de construcción de mundos plausibles. Diferencias en la abstracción del discurso, paradojas, invocaciones, hipótesis no verificables, etc. abundan en las definiciones de la situación que proponen los distintos paradigmas. La validez de éstos es referida de preferencia a su plausibilidad teórica y su valor heurístico a la capacidad de señalar tópicos relevantes y significativos, en este caso relativos al diseño y reconstrucción institucional del Estado.

Los paradigmas construidos por los científicos sociales son de "segundo orden" porque se apoyan en un material pre-interpretado y presuponen capacidades conceptuales en los actores a cuya conducta se refieren. Anthony Giddens ha acuñado el término "doble hermenéutica" para referirse al doble proceso de traducción o de comprensión que aquí interviene. Al decir de Giddens, "es tarea de las descripciones sociológicas mediar entre los marcos de sentido en cuyo interior los actores orientan su conducta. Pero esas descripciones son categorías de comprensión que también requieren un esfuerzo traductor dentro y fuera de los marcos de sentido que convienen a las teorías sociológicas" ${ }^{24}$.

Se presume en este contexto que los actores legos conocen más que lo que comúnmente se sospecha acerca de las condiciones y antecedentes que informan un determinado proceso. Desde el saber práctico pueden organizar su experiencia e inferir muchos aspectos que están incluidos en el saber discursivo o especializado. Por su parte, es de la naturaleza de la ciencia social que sus conceptos pasen a ser conceptos de "primer orden" si de ellos se

${ }_{23}^{23}$ Thomas S. Kuhn, 'La Estructura de las Revoluciones Científicas'.

${ }_{24}$ Anthony Giddens, 'La Constitución de la Sociedad', Amorrortu Ed. Argentina, 1995, pág. 310. 
apropia la vida social. Ejemplo de lo que se afirma es la noción de racionalidad económica y probabilidad de socialización en la figura "homo economicus", eventos impensables sin la batería de categorías, supuestos e hipótesis desarrollados por la economía política desde fines del siglo XVIII hasta nuestros días.

Como en la vida cotidiana, por tratarse de concepciones globales que fijan una 'visión de mundo' y hablan sobre la significación de instituciones y acontecimientos, habitualmente los paradigmas son formulados a diferentes niveles de abstracción y sus enunciados implican distintos tipos de proposiciones. En todo paradigma se combinan y a veces se confunden la propuesta de hechos con deducciones teóricas y con tesis de valor. Lo que para un paradigma constituye un hecho firme y confirmado, para otros no constituye más que un supuesto o juicio de valor. De aquí, las dificultades de establecer correspondencias entre las proposiciones de uno y otro paradigma.

Teniendo como telón de fondo el diagnóstico descrito en el capítulo anterior sobre la nueva matriz emergente en las relaciones de trabajo en Chile, corresponde ahora discutir algunos paradigmas de diseño estatal pertinentes al tema de la modernización del Estado. Estos son confrontados con entrevistas en profundidad y grupos de discusión de agentes estatales. Cada instancia tiene sus propios atributos. Así, mientras el tema de la modernización del Estado está a lo menos "en hueco" en los distintos paradigmas y en documentos oficiales, otra es la situación con respecto a los agentes estatales.

Tratándose de un tema transdisciplinario, el principal criterio para seleccionar los paradigmas fue su aparente vigencia en el debate académico y su capacidad de seducir y cautivar (o defraudar) la cabeza y sentimientos de hombres y mujeres. El otro criterio asumido es el concepto que postulan sobre la democracia. Entre los paradigmas seleccionados algunos toman Ia democracia principalmente como un régimen de gobierno que cuenta con los medios de regulación (derecho y dinero) y ponen énfasis en la capacidad de gobierno de la democracia a fin de que ejerza un mando técnicamente correcto. Se afianza una visión del Estado desde la economía política y en la lógica del mercado autorregulado. Allí, la racionalidad técnica y/o sistémica pasa a ser el primado fundamental de la política. Estos paradigmas constituyen fuentes de una doctrina ortodoxa de la modernización Para otros paradigmas, en cambio, la democracia es ante todo un régimen que se debe a la votación popular y basado en mecanismos representativos y participativos. Ciudadanía y derechos del ciudadano constituyen su énfasis básico. Algunos de éstos adhieren a una visión procedimental de la democracia, en tanto que otros ponen énfasis en sus aspectos sustantivos. En cualquier hipótesis, en este ámbito la racionalidad técnica pasa a estar mediada por la racionalidad social y política.

La modernización del Estado implica diseños políticos y técnicos organizados teóricamente. Al tratarse de un proceso que responde a megatendencias mundiales, muchos aprontes arrancan de experiencias relativamente exitosas que se quieren aplicar dogmáticamente a otras latitudes, sin tener en cuanta las diferencias de contexto. Pareciera que todo se justifica en nombre de la globalización. En la investigación se intentó identificar el origen aunque sea remoto de algunas expresiones locales.

En definitiva, se utilizaron como origen de modelos alternativos de servicio público los siguientes esquemas teóricos: la Escuela de Opción Pública, el Paradigma de Igualdad Democrática, el Enfoque Sistémico y la Estrategia de la CEPAL para América Latina en los 
años 90. En la medida que la teoría marxiana constituye una caracterización general y apronte crítico del Estado capitalista, corresponderá a otro momento retomar ese enfoque, cuando se privilegie teorías que ponen un énfasis contrafactual de la modernización. Lo mismo es válido para la discusión de teorías contemporáneas que recuperan y propugnan el viejo ideal ateniense de la "ciudad buena" o "vida buena".

\section{La Escuela de Opción Pública.}

La ofensiva ideológica del neo-liberalismo que se asocia a la modemización ha representado un fuerte repunte de las doctrinas contractualistas acerca del Estado. Rawls sostiene que las doctrinas contractualistas se dividen hoy según afirmen una sola concepción del bien, que ha de ser reconocida por todas las personas en la medida que son racionales; o si admiten pluralidad de concepciones, opuestas e incluso inconmensurables. La primera doctrina está representada por el utilitarismo clásico y su versión contemporánea, la Escuela de Opción Pública; la segunda concepción es reivindicada por la moderna teoría de justicia como equidad, de la cual el mismo Rawls es su principal exponente ${ }^{25}$.

La Escuela de Opción Pública ${ }^{26}$ constituye el fundamento teórico del homo economicus y un desplazamiento radical de los supuestos de la economía neo-clásica al ámbito de la política. Requiere de un mínimo de premisas éticas: i) los individuos son las entidades filosficas relevantes; ii) todos los individuos son igualmente capaces de elegir; iii) el individuo representativo o "medio" está motivado por interés egoísta, del mismo modo que suis comnañeros; iv) todos quieren "más" que "menos" y tratan de maximizar su propia utilidad :eniendo distintas funciones de utilidad. Como método tiende a destruir cualquiera diferen-ia lógica entre lo público y lo privado de la actividad humana. La acción colectiva y privada sstá motivada por fines concebidos individualmente y toda acción procede luego de un cálculo mental de individuos.

Mercado y Estado son mecanismos donde la cooperación se hace posible. Los mismos alores motivan a los individuos en ambos casos. Se reconocen como condiciones pre-consitucionales básicas la propiedad privada y la asignación de derechos individuales. El agente Estado surge sólo debido a conflictos entre intereses individuales. "Igualdad ante la ley" Expresa la norma de un orden social individualista. Se trata de una norma de igualdad entre ¿esiguales.

El economista supone que el individuo medio es capaz de clasificar y ordenar todas las - ombinaciones altemativas de bienes y servicios a su alcance y que este ordenamiento es ansitivo. Al enfrentar paquetes de bienes se introduce la hipótesis de la sustitución margial decreciente o de la relativa utilidad marginal decreciente. Por analogía, se puede afirmar - $\mathrm{u}$ el individuo procede con los bienes públicos o colectivos del mismo modo que con los anes privados. Los bienes públicos son definidos por su condición de indivisibles, no ex- isivos y de consumo conjunto. No obstante estas propiedades, existe relación marginal acreciente entre bienes públicos y privados, por una parte, y entre bienes solo públicos por $\therefore$ otra.

Juhn Rawls. "La justicia como equidad", Editorial Tecnos. 1986

Aq̣uí se desarrolla una discusión relativamente libre de los clásicos de la teoría. En especial Buchanan y Tullock "El cáleulo del zinso" y Buchanan "Los límites de la libertad". 
Especificando la estructura básica de acción política en la Escuela de Opción Pública se obtiene lo siguiente: por una parte, individuos egoístas que a través de distintos procedimientos ponen de manifiesto preferencias por políticas gubernamentales: las preferencias son conocidas a priori, son exógenas y no contingentes al proceso político mismo y todas las coaliciones entre ellas son igualmente posibles. Como contraparte, existen equipos de individuos también egoístas que compiten por apoyo político. Individuos y "políticos" son racionales en el sentido que recíprocamente venden apoyos y compran beneficios en términos óptimos o próximos a la maximización de su respectivo bienestar. Todos desean como en el comercio "más" que "menos" y por efecto del intercambio se maximiza el bienestar general. Individuos y políticos no establecen discriminación alguna entre lo público y lo privado.

Un tema que se deduce directamente del modelo teórico es la decisión de los individuos sobre el nivel de actividad gubernamental o de "regulación". La tesis central es que en el proceso democrático el Estado es fuente de ineficiencias y que el mercado asigna recursos en todos los casos más eficientemente que las instituciones políticas. Los teóricos de la opción pública fundamentan sus planteamientos criticando algunos supuestos neoclásicos. Según estos últimos, la sociedad está bien cuando los mercados cumplen con los equilibrios competitivos. Esta condición puede fallar por problemas de costos, de información y externalidades. Ante fallas del mercado, la economía neoclásica acepta al Estado u otra institución política como agente de regulación. La réplica de la Escuela va por el lado de reducir las fallas de mercado a cuestiones extra-mercado del siguiente tenor: la economía funciona en un mundo incierto, problemas de definición de derechos de propiedad y remarcando que si el mercado no funciona eficientemente no hay garantías para pensar que el Estado lo haría mejor.

Otros ámbitos relevantes levantados por esta Escuela son los temas grupos de interés y burocracia estatal.

G. Stigler ${ }^{27}$ es el principal exponente de la teoría sobre el Estado y los grupos de interés. Define al Estado como "agencia monopólica de coacción legal", lo cual le permite hacer cosas que hasta el más poderoso de los ciudadanos no puede hacer. Esta condición factual crea el peligro que sea colonizado por grupos que pueden usarlo en beneficio propio, los grupos de interés. Stigler señala tres mecanismos de apropiación de recursos del Estado: subsidios directos, barreras de entrada de nuevos rivales y restricciones al comercio internacional. Se parte de la premisa que cuando un grupo de interés recibe recursos del Estado, los beneficios que éstos generan son menores que los costos que soporta la sociedad. Según Olson $^{28}$, los grupos de interés son responsables del estancamiento del crecimiento económico y la eventual declinación de las naciones.

No es mejor la visión de la Escuela sobre la burocracia pública. La importancia de una administración está ligada directamente al presupuesto que maneja, como asimismo de las unidades que dependen de ella. A mayor presupuesto mayor prestigio. A mayor cantidad de unidades bajo su esfera de control, mayor será su presupuesto. De aquí que, independiente de sus objetivos, toda unidad administrativa tiene tendencia natural al crecimiento y despilfarro.

${ }^{27}$ G. J. Stigler, "The Theory of Economic Regulation", en Chicago Studies in Political Economy, Stigler Ed. University of Chicago. 1988

"M. Olson Jr. "The Rise and Decline of Nations". Yale University Press. 1982. 
Como síntesis de este paradigma se puede sostener lo siguiente: desde el enfoque de la opción pública los costos y beneficios de "regular" constituyen el centro fundamental de las políticas públicas y la evaluación de éstas pasa por la interacción entre burocracia pública. grupos de interés, mercados políticos y fallas de mercado. El "regulador" es una entidad puramente exterior y subsidiaria de una economía de mercado, cuyo agente racional u "homo economicus" tiene preferencias fijas y exógenas al proceso político. de donde todas las coaliciones son posibles en la generación del consenso. El Estado debe propender a sólo encaigarse del control de las variables macroeconómicas, de modo que se mantengan dentro de un rango de valores constantes (ceteris paribus). De modo subsidiario debe atender a las variables no económicas. Incluso estas funciones deben estar sometidas al escrutinio de costos y beneficios y sustituciones marginales, to cual define los niveles do eficiencia posibles, único y real objetivo de la política pública.

La Escuela de Opción Pública puede ser entendida como una ingeniería política del "laissez-faire" contemporáneo. Su visión última de la sociedad es un esquema circular de familias consumidoras y empresas productoras sin más mediaciones que ei mercado. Políticos, burócratas, empresarios y trabajadores organizados son visualizados como eventuales colonizadores del Estado. Este atributo ligado a su énfasis maximizador plantea a la Escuela una ambiguedad con respecto a la concepción clásica de la democracia. Aboga por una suerte de "democracia directa" que se da ideal y cotidianamente en el mercado. De aquí que virtualmente es compatible con soluciones de fuerza y regímenes autoritarios para hacer viable su hegemonía cultural y política.

En el marco de las relaciones laborales esta Escuela tiene propuestas simples y restrictivas. Los agentes económicos son reducidos a factores de producción y sus relaciones regiJas por las leyes de oferta y demanda. La empresa pasa a ser el escenario para la organiza:ión de la cooperación social, teniendo allí el empresario plena potestad contractual de inversión, gestión, administración y control. Capital y Trabajo son categorías totalmente autónomas y están orientados individualmente por el criterio de maximización del beneficio y la utilidad. En este campo al Estado no le cabe más que regular el pleno funcionamiento del mercado, velando por la más libre movilidad de capital y trabajo. De darse esta condición se puede esperar la maximización de la utilidad total definida ésta en términos homogéneos de jienestar.

Apelando siempre por un Estado lo más pequeño posible y bajo especiales circunstancias la escuela acepta la regulación aplicando el principio de subsidiaridad. Fenómenos como a extrema pobreza ameritan políticas sociales, altamente focalizadas que no alteren las condiciones de funcionamiento del mercado de trabajo. Trabajo y condiciones de sobrevivencia ion, por tanto, dimensiones que responden a parámetros distintos e incluso hastacontradic:orios.

Douglass C. North ${ }^{29}$ intenta una especificación de la noción de racionalidad utilizada zor la teoría de opción pública. Sin abandonar del todo la perspectiva, este autor se plantea 21 terreno en que el modelo es útil. Problemas simples, información completa, situaciones apetitivas y motivación fuerte generan condiciones que se prestan para estos modelos. Los mercados políticos incluso en países con población altamente informada difícilmente o nuna responden a estas condiciones. A medida que nos alejamos de estas condiciones. dice

Douglass C. North, "Qué queremos decir cuando hablamos de racionalidad?", en Public Choce N"77. 1993. Traducido at piñol por Estudios Públicos No $53,1994$. 
North, se deben explorar las clases de instituciones que en tales condiciones surgirán para estructurar la interacción humana.

\section{El Paradigma de Igualdad Democrática.}

La reflexión sobre el Estado de Derecho ha dado origen en los últimos años a una teoría procedimental de la justicia. Los nombres de K.O. Apel, Jürgen Habermas, L. Kohlberg y John Rawls son identificables con este modelo de formación imparcial de la voluntad colectiva. En este contexto, Rawls ${ }^{30}$ representa la concepción de la justicia como equidad o paradigma de igualdad democrática.

Según Rawls, el curso del pensamiento democrático durante los dos últimos siglos muestra que el entendimiento de la libertad y la igualdad y el modo más adecuado de equilibrar las pretensiones (de validez) de esas nociones, no han alcanzado expresión que encuentre aprobación general. Qué decir de la fraternidad, la que no ha recibido atención alguna en la teoría política moderna. De aquí que el autor se proponga zanjar un desacuerdo fundamental acerca de la forma justa de las instituciones básicas dentro de una sociedad democrática que se desenvuelve en condiciones modernas. Democracia y Modernidad son dos referentes básicos de su teoría. Su tarea es hacer explícitas y articular nociones y principios compartidos que se piensa están latentes en el sentido común y son implícitos en la cultura pública de una democracia.

En relación a la escuela de opción pública, el contractualismo de Rawls representa críticas y reformulaciones particularmente importantes.

1. Ante todo, se distancia radicalmente del utilitarismo en general y de la escuela en particular por la falta de respeto de éstas a las personas. No obstante su individualismo metodológico, en el utilitarismo una persona no es considerada valiosa por derecho propio, constituye sólo una pieza en el gran engranaje de la maximización de la utilidad social general. Se podrían aceptar bajos niveles de utilidad para algunas personas si eso es parte de una situación que maximiza la utilidad total ${ }^{31}$.

2. Establece como objeto de la teoría de la justicia la estructura básica de la sociedad. El funcionamiento conjunto de las instituciones influye en el reparto de los beneficios, en especial de bienes primarios. Estos bienes son: i) libertades de pensamiento y conciencia; ii) libertad de movimiento y libre elección de ocupación; iii) poderes y prerrogativas en cargos de responsabilidad; iv) renta y riqueza como medios omnivalentes; y $v$ ) bases sociales del respeto de sí mismo.

3. Deriva dos principios para asignar derechos y deberes y para regular cuotas distributivas en la medida que éstas estén determinadas por instituciones fundamentales de la sociedad. Estos principios llevan inscrita una idea democrática de la justicia.

El primero, principio de la igual libertad, cada persona ha de tener un igual derecho a la

\footnotetext{
${ }^{31)}$ En la discusión sobre el paradigma de iguaidad democrática nos hemos apoyado en las siguientes obras de Rawls, "Teoría de la Justicia" y "La Justicia como Equidad".

31 Jon Elster, 'Justicia Local'. Ed. Gedisa. España 1994.
} 
más amplia libertad compatible con una similar libertad para todos. El segundo, principio de la diferencia, las desigualdades económicas y sociales (en tanto que Jefinidas o fomentadas por la estructura institucional) han de satisfacer dos zondiciones: i) ser para el máximo beneficio esperado del menos favorecido (criterio maximun); ii) ir adscritas a cargos y posiciones accesibles a todos en condiciones te equitativa igualdad de oportunidades.

4. Al priorizar el principio de la igual libertad por sobre el de la diferencia -evitaliza al liberalismo contra toda forma de autoritarismo. Incluso en el marco de -na democracia constitucional, Rawls contempla condiciones que justifican la Lesobediencia civil. Lo razonable puede entrar en contradicción con lo racional. Cualquier arreglo institucional que garantice un mayor bienestar para todos no se ustifica si implica reducir la libertad de algunos. Se concluye que en esta teoría la usticia está por sobre la eficiencia.

5. Al atender al principio de la diferencia abre un amplio espacio a cuestiones te justicia distributiva. A este respecto Rawls especifica su distancia con la escuela ¿e opción pública. Requeridos en su concepción de lo que preferirían individuos -acionales en una "posición original" y bajo un grueso velo de ignorancia, Rawls zree que optarían por la distribución que los llevaría a la mejor situación posible si, - uando se levanta el velo, se encuentran en la posición del peor. Los utilitaristas, zor el contrario, estiman que se creerían con iguales probabilidades de ocupar cada zosición y, por tanto, elegirían la distribución con el nivel promedio de bienestar más elevado.

En un ejercicio comparativo, Rawls selecciona cuatro sistemas que - $>$ entualmente pueden informar una estructura social básica: el sistema de libertad ratural, el sistema de igualdad liberal, el sistema de aristocracia natural y el sistema Je igualdad democrática. Estos representan distintos aprontes con respecto a la - ustificación de criterios de distribución o al segundo principio de justicia. Habiendo ostenido que los dos principios de la justicia llevan inscrita una idea democrática de la justicia, el sistema de igualdad democrática es superior a las otras concepciones. El orden social fundado en estos principios no debe asegurar las más atractivas zxpectativas de los mejor situados salvo que ello sea en provecho de los menos a fortunados; o en términos negativos, cuando una disminución de sus ventajas haría zue los menos afortunados se encontraran aún peor de lo que están. Supuesta esta condición, las cuotas distributivas no se ven inadecuadamente influidas ni por zontingencias sociales ni por la lotería de los activos naturales.

Abocado al tema de diseño institucional, Rawls responde que éste intenta irticular las instituciones de una democracia constitucional de modo de satisfacer el principio de la diferencia y apunta idealmente a ser capaces de afirmar que, tal zomo funciona actualmente el sistema social, las desigualdades que permite zontribuyen al bienestar de cada uno. Aboga por el fortalecimiento de una cultura y espacio público democráticos altamente deliberativos en materia de justicia y equidad. 
A diferencia de la escuela de opción pública es partidario de un gobierno democrático particularmente activo en sus funciones de control y regulación de una economía de mercado.

Cabe imputar a la teoría una fuerte correspondencia entre modernización y democratización. Una sociedad será más democrática en la medida que cultural y socialmente se hagan explícitos y compartidos los principios de la justicia. Será más moderna si estos principios informan factualmente la estructura básica de la sociedad y se hacen compatibles con criterios de eficiencia.

En el marco de las relaciones laborales la teoría tendería a privilegiar principios que están gobernando los procesos de cooperación y distribución. Supone una situación previa a toda institucionalización, pues al decir de Habermas ${ }^{32}$ "inserta en la descripción de la "posición original" las restricciones normativas bajjo las que el egoísmo racional de partes libres e iguales acaban conduciendo a la elección de principios normativamente correctos". Convocatorias abiertas para discutir agendas públicas de diálogo social inducidas por los propios ciudadanos y con apoyo de los medios de comunicación (publicidad) harían posible activar procedimientos de participación y acuerdos en torno a valores y principios democráticos. En estas agendas, el tema central sería el sistema institucional y en particular las instituciones relativas al trabajo.

A diferencia de la escuela de opción pública, Rawls permite en los ejercicios distributivos no utilizar un bien homogéneo como el ingreso o el bienestar, sino un haz multidimensional de bienes primarios. Elster sostiene que en ausencia de una moneda común con la que puedan medirse todos los haces de bienes, la teoría de Rawls corre el riesgo de indeterminación. Al parecer no intenta resolver el problema ${ }^{33}$.

\section{El Paradigma Sistémico.}

La teoría de sistema, principalmente en su variante cibernética y de investigación operacional, es un enfoque sociológico que ha sido reformulado sustancialmente por Niklas Luhmann a un alto nivel de abstracción teórico ${ }^{34}$.

El reconocimiento de la complejidad material y social es el punto de partida de Luhmann. Esta la entiende como la "sobreabundancia de relaciones, posibilidades, conexiones", de modo que no es posible plantear una correspondencia biunívoca y lineal de elemento con elemento.

El instrumento de reducción de las expectativas asociadas a la complejidad o "exceso de posibilidades del mundo" es el sistema. El sistema humano sirve de arquetipo para entender el modo de funcionamiento de los sistemas sociales. Estos se distinguen por estar "constituidos por acciones efectivas que se relacionan a través del sentido", es decir, un sistema social es una red de acciones que se refieren recíprocamente y que son delimitables frente a un entorno o ambiente. Al igual que el sistema humano, los sistemas sociales realizan parte

\footnotetext{
32 Jürgen Habermas, 'Escritos sobre moralidad y eticidad', Paidós 1991 pág. 161.

${ }^{33}$ Elster, op. cit.

${ }^{34} \mathrm{Al}$ jgual que en el caso anterior, aquí se desarrolla una discusión relativamente libre de las obras más pertinentes del autor, en especial "El sistema social" y "La teoría política del Estado de Bienestar".
} 
de las posibilidades que le provee el ambiente y "reducen" las posibilidades excedentarias valiéndose de selecciones. El principal problema del sistema es mantener la organización constante respecto de un entorno altamente complejo.

Los sistemas reunen dos atributos fundamentales: auterreferencia y autopoiesis. El concepto de autoreferencia, proveniente de la cibernética, implica que los sistemas se definen por la diferencia respecto a su entorno, incluyen en sí mismo el entorno y sólo pueden entenderse en cuanto sistema desde esa diferencia. La autopoiesis o autocreación significa que los sistemas pueden crear su propia estructura y los elementos que lo componen. Los cambios en la estructura no cambian necesariamente la identidad del sistema

Al hacer dependiente la relación sistema-ambiente de selecciones, el mundo se hace contingente, esto es, las posibilidades seleccionadas por el sistema son eventualmente realizables también de modo distinto a como se espera. Este riesgo o peligro de defraudación de expectativas pone al sistema frente al tema de la seguridad como su problema central. Los istemas sociales, por tanto, deben poder indicar a los actores qué comportamientos de los tros son posibles y probables. La estructura es el mecanismo que selecciona en los sistemas intre las alternativas posibles de conducta un restringido campo de alternativas probables. Para regular el "miedo" a la defraudación, la estructura realiza una primera selección de lo cosible sobre la que el actor individual puede realizar una segunda selección consciente y implificada.

La sociedad en su conjunto es definida como un complejo de sistemas, más o menos -structurados internamente, que conforma un patrimonio de preselecciones de códigos y $\therefore$ ciones comunes a las que pueden recurrir los individuos en las diversas situaciones. Con - Lo puede garantizar un mínimo de prestaciones reductivas y de seguridad y satisfacer la - acesidad de mantener estables los sistemas a pesar del exceso de posibilidades de su amEnte. Códigos y acciones comunes se traducen en comunicaciones. En la medida que los -dividuos no están incluidos plenamente en los sistemas, sino por el contrario son eventuas o mantienen una relación puramente fragmentaria a éstos, forman parte del entorno o madio ambiente de los sistemas.

La sociedad moderna se caracteriza por su alta diferenciación funcional. Los sistemas $\therefore$ sponden a esta diferenciación y cada sistema desarrolla un sentido o racionalidad propia y - ircial. Los sistemas no pueden actuar directamente sobre el medio ambiente, sólo pueden - tuar sobre sí mismos. Así, el cambio social que surge del juego sistema-entorno se sustrae : Ina previsión y control precisos y en ello coopera el entorno. Como paradoja, lo que en un - ancipio puede ser querido aparece después, a la vista de los resultados, como algo que es veciso soportar.

Luhmann levanta el tema de la política y del Estado a partir de la noción Estado Social Derecho, el cual tiene expresión constitucional con la fundación de la República Federal - Alemania. Esta figura une de manera explícita la estructura Estado a un contex to históriY de sentido definido: la política. Así, Estado y política constituyen una unidad sistemaromo indisoluble, de modo que la política es mediadora y presenta la sociedad al Estado. : dinámica de esta relación produce "lo social" a través de la tematización operativa de la zica propia del Estado de Bienestar: la compensación de las desventajas o labor restitutiva condiciones de existencia que se consideran originarias o ideales. 
Toda política es comunicación y toda comunicación es autoreferente. habla también sobre sí misma. Esta condición hace posible que la política aprecie en el sistema político lo que sea su entorno. Y si el entorno, ya sea como economía, educación ! límite de recursos naturales, adquiere una importancia creciente, ¿puede aumentarse la capacidad de comunicación del sistema político o se encuentra ante límites insuperables a causa de su autoreferencia? A este respecto Luhmann elige dos caminos de respuesta.

La diferenciación interna lleva a privilegiar en el sistema político diversas formas de orientación hacia el exterior. La recepción de información (input) se guía no sólo por su contenido objetivo, sino por determinados sensores o filtros, esto es, por la opinión pública, por las posibilidades de consenso y de fomento de la carrera de importantes personalidades políticas y por el derecho. Las informaciones que no pueden satisfacer ninguna de estas condiciones de recepción no tienen apenas posibilidad de encontrar atención política. La sensibilidad del sistema se guía por estos filtros. Estos son flexibles y no están predispuestos hacia determinados temas.

La segunda reflexión parte del hecho de que para la decisiones políticas o función vinculante (output), en el Estado de Bienestar sólo se dispone prácticamente de las formas de acción del derecho y el dincro. O bien se sujeta el comportamiento (de la burociacia o el ciudadano) mediante la imnosición del derecho o bien se utiliza el dinero para obtener o inducir determinados comportamientos. Según Luhmann ambos medios de comunicación, derecho y dinero, muestran claros síntomas de utilización excesiva y se les aplica a tareas para los que están poco indicados, en especial en el ámbito de la educación y la política social

Las condiciones precedentes hacen que el diagnóstico acerca del Estado de bienestar sea caracterizado como "sobrecarga del sistema político sobre sí mismo". Bajo esta sobrecarga existen motivos socio-estructurales establecidos de modo prácticamente irreversibles. De una parte, cuando dentro de una sociedad se diferencia un ámbito funcional para la política como sistema autónomo, apenas encuentra en sí mismo razones para limitar la realización de su función propia. De la otra, ha aumentado inmensamente en todos los ámbitos de la vida la dependencia del ciudadano de la política; éxitos y fracasos, planificaciones y presuntas necesidades de la política se transforman muy rápidamente en destinos individuales.

Luhmann distingue entre una concepción expansiva y otra restrictiva de la política en el Estado de Bienestar. La primera sería desconcertantemente conservadora en tanto que la segunda rompería con la tradición. La concepción expansiva le asigna a la política un papel rector en la sociedad, sería destinataria última de todos los problemas sin resolver, una suerte de cima jerárquica de la sociedad, la última instancia. Una concepción restrictiva, por el contrario, ve en la política únicamente una función entre muchas otras. Hace su aportación vinculante a la vida social del modo más eficaz posible. Pero es consciente de los límites de sus posibilidades y corresponsable de estos límites. Una política restrictiva hace posible que se determine con precisión qué aspectos de la economía, la educación, la ciencia, la vida familiar, etc. dependen de la política.

La concepción restrictiva de la política es congruente con la visión de Luhmann acerca de la democracia. A su modo de ver, la democracia representa un logro evolucionario altamente improbable: la escisión de la cima del sistema político, diferenciado por la distinción gobierno-oposición que pasa a constituir el código $(+-)$ del sistema político. La condición 
de posibilidad de la democracia es una sociedad articulada horizontalmente en sistemas funcionales. Perdida la jerarquía estamentaria, la política se hace autónoma, pierde la capacidad de la representación y alcanza el acceso a su propio código. En este proceso de diferenciación la autoridad de la verdadera opinión es ocupada por una opinión pública que favorece ora al gobiemo ora a la oposición. La ganancia estructural de todo esto residiría en la inestabilidad y la resultante mayor sensibilidad del sistema. La democracia es, en consecuencia, una invención estructural que opera como un sistema cerrado o autopoiético: que debe codificarse y programarse hacia la contingencia. La función vinculante de la democracia es incorporar a la política la perspectiva de los afectados.

La modernización del Estado puede entenderse en este contexto como un proceso de diferenciación funcional donde la democracia adquiere su propio código y el Estado una particular capacidad de reflexión acerca de sí mismo y su diferencia con el entorno. La visión sistémica se perfila, entonces, como un intento operacional para establecer una relación de eficiencia entre un ambiente ya estructurado en sus comunicaciones: economía de mercado, "homo economicus", mercado de trabajo, etc. constituido como sistema y con su propia semántica reductora de complejidad y una estructura sometida a las presiones de redefinición de su entidad como sistema. Así, el problema estatal es redefinido en términos de su estructura interna y sus procedimientos. En este contexto, la teoría se convierte en un jotente instrumento de reflexión acerca de la diferenciación y racionalización administrativa en un medio ambiente de creciente complejidad.

La preparación para la contingencia exige al Estado la elaboración de sus elementos de Jecisión básicos: la normatividad y su capacidad de prescribir órdenes legítimos. En términos de relaciones laborales, capital y trabajo constituyen para el Estado un problema de Jerecho que limita contingencia entre dos sistemas en interacción. En cuanto autoridad al Estado le compete la definición de límites de las relaciones laborales y no los contenidos de esta relación, lo que reformula el tema en una instancia estrictamente jurídica: definición de las relaciones, contrato, normas laborales, negociación, seguridad del trabajo, etc.

La teoría de sistema que se comenta ha recibido numerosas críticas por su carácter autoreferencial. Jürgen Habermas ${ }^{35}$ observa que esta teoría hace que el derecho (y el poder político a su través) pueda cerrarse sobre sí mismo (clausura operacional) controlando sus propias condiciones de legitimidad o haciendo esta cuestión ociosa. En contra de esta tesis, afirma que, muy por el contrario, derecho y poder están expuestos al "poder comunicativamente generado" en los múltiples espacios públicos en que la práctica social tiene su forma de reflexión y en los espacios de discusión, argumentación y obtención de compromisos previstos en el propio sistema jurídico y político.

\section{La Estrategia de la CEPAL para la Región.}

La nueva estrategia de la CEPAL fue inicialmente formulada en un documento publizado en 1990 denominado "Transformación productiva con equidad. La tarea prioritaria de América Latina y el Caribe en los años noventa" ${ }^{\natural 6}$

\footnotetext{
Jürgen Habermas, op. cit.

Otros escritos posteriores de la institución y complementarios a estos planteamientos son CEPAL-CELADE "Equidad y -.unsformación productiva", "Educación y Conocimiento: Eje de la transformación productiva" 1992, etc.
} 
La CEPAL arranca de la constatación que el crecimiento económico no conduce de manera necesaria y automática a la equidad. Sin embargo, argumenta que un crecimiento con equidad, ambientalmente sustentable y en democracia no solo es deseable, sino también posible. Es más: así como la equidad no puede alcanzarse en ausencia de un crecimiento sólido y sostenido, el crecimiento exige un grado razonable de estabilidad socio-política y ésta implica cumplir con requisitos mínimos de equidad. De este condicionamiento recíproco se desprende la necesidad de avanzar hacia ambos objetivos en forma simultánea antes que secuencial.

El enfoque de la CEPAL se entiende integrado por cuanto ambos objetivos, crecimiento y equidad, informan tanto a la política económica como a la política social. Implica, por una parte, preferir aquellas políticas económicas que favorecen no solo el crecimiento sino también la equidad y, por otra, destacar en la política social el efecto productivo y de eficiencia, no solo de equidad. El énfasis en la complementación de objetivos, como una sola tarea, permite aprovechar muchas oportunidades de acción.

Por equidad la CEPAL entiende avances en al menos uno de los tres objetivos siguientes. El primero es minimizar la proporción de personas y hogares cuyas condiciones de vida se ubican por debajo de lo que la sociedad considera aceptable económica, social y políticamente. El segundo es promover el desarrollo de los talentos potenciales existentes en todos los grupos de la sociedad, eliminando progresivamente los privilegios y las discriminaciones jurídicamente establecidas, así como la desigualdad de oportunidades de cualquier tipo, incluyendo aquellas asociadas al origen social, étnico o geográfico, o bien al sexo. El tercero es buscar que ni el poder o la riqueza, ni tampoco los frutos del progreso, se concentren de tal manera que se restrinja, para las generaciones futuras o presentes, su ámbito de libertad.

Al centro del planteamiento de la CEPAL se encuentra la transformación productiva sustentada en una incorporación deliberada y sistemática del progreso técnico. Se requieren mejoras en la capacidad empresarial y, sobre todo, en la educación y capacitación de la mano de obra. Lo que se hat en las empresas pequeñas y medianas es especialmente importante, por cuanto emplean el grueso de la mano de obra y son responsables de buena parte del producto en la región. Si bien este proceso incluirá elementos de innovación, se recomienda la adaptación e incorporación de tecnologías existentes.

El segundo eje es el logro del pleno empleo productivo pues es el principal mecanismo de contribución y participación en los frutos del desarrollo. El cambio tecnológico debe ser evaluado en términos de su impacto en el empleo. Una tecnología que genere mayor nivel de empleo por unidad de producto puede ser económicamente más provechosa y de mayor productividad total si permite ahorrar suficiente capital. El enfoque integrado descarta como ilusoria la posibilidad de un crecimiento liderado por el sector informal de la economía, por cuanto la masa salarial del sector informal esta en función directa del crecimiento de la actividad formal. Sin embargo, reivindica en el sector informal la presencia de numerosas capacidades latentes, como por ej. destrezas empresariales.

El tercer eje pone especial énfasis en la educación y el conocimiento, no solo como servicio social básico, sino como pivote del progreso técnico. De ahí que para conciliar eficiencia con equidad sea imperativo mejorar la calidad de la educación y asegurar a todos los estratos sociales un acceso similar. En este ámbito es esencial aumentar la descentralizacion y las autonomías locales, con las asignaciones distributivas complementarias que ello 
implica. Una reforma educacional significativa requiere un compromiso financiero estable de parte de la sociedad.

Las principales áreas de política que privilegia la CEPAL incluyen el progreso técnico. la inserción internacional, el proceso de ahorro e inversión, los mercados de trabajo, la politica social y la participación.

Con respecto al mercado de trabajo la CEPAL estima que es necesario realizar cambios sustanciales en las relaciones laborales. Las tendencias del mercado requiere reemplazar progresivamente en las empresas las estructuras verticales y jerárquicas por otras con esquemas más horizontales y flexibles, que se caracterizan por un intensivo intercambio de información, a fin de aprovechar mejor la iniciativa, creatividad y responsabilidad de la fuerza de trabajo. Modemizar las relaciones laborales implica, por una parte, que la empresa trate a los trabajadores como socios colaboradores, más que como factores de producción. Por otra, supone un movimiento sindical tecnificado, consciente que su adversario no es tanto el empresario como la competencia y que, por tanto, sus objetivos deben incluir mejoras de la productividad.

La CEPAL es partidaria de los "salarios participativos". Estos no sólo estimulan la mejora de la productividad, al pagarse una parte del salario en forma variable contra utilidades, ventas, u otros sino que tiende a estabilizar e incluso a acrecentar el empleo.

Ligada a la política social y las transferencias, particularmente importantes resultan los programas de inversión social destinados a romper la transmisión intergeneracional de la pobreza. Con respecto al mercado laboral, aquí se recomienda ampliar los programas de capacitación de modo que cada trabajador tenga acceso a ellos no una, sino varias veces a lo largo de su vida laboral.

En el mismo tenor anterior, se recomienda también privilegiar transferencias que contribuyan a incrementar el ingreso familiar, más que el individual, centrando estos beneficios en bonificaciones a los jefes de hogar de más bajos ingresos. Este sería un mecanismo para elevar los ingresos de manera más digna, pues se complementan los ingresos de la familia, estando el jefe de hogar ocupado, a diferencia de otros subsidios que se otorgan solo si éste no está ocupado.

Lograr un equilibrio entre crecimiento y equidad significará abandonar tanto la tentación tecnocrática, que no toma en cuenta las demandas sociales, como la populista que impone el voluntarismo por sobre la técnica. El curso que parece indicado es el de movilizar los instrumentos más legítimos de la democracia: la participación y la concertación. Lo difícil en la coyuntura actual según la CEPAL es que no solo se trata de promover la organización de los que hasta ahora han Estado excluidos para que el programa tenga viabilidad política, sino fomentar su participación responsable, pues obviamente no será posible satisfacer en el corto plazo todas sus demandas postergadas.

El tema del Estado surge en el esquema estratégico de la CEPAL junto al panorama internacional y la estabilización como factores condicionantes al enfoque integrado. La estrategia requiere una reestructuración sustancial del Estado. Debe abandonar muchas funciones, principalmente en la esfera productiva, y asumir vigorosamente funciones claves, 
como son el manejo macroeconómico, la inversión social y distributiva, el apoyo a la inserción internacional y la incorporación del progreso técnico al proceso productivo y la defensa del medio ambiente.

La política fiscal es un eslabón fundamental entre las políticas económicas y sociales. Importante es poder conciliar el equilibrio fiscal sobre bases sólidas y permanentes. Buena parte del esfuerzo potencial de las políticas sociales, tanto de inversión en capital humano como de seguridad social y transferencias, dependerá de si se recaudan suficientes recursos para destinar a estos fines. De aquí que se postula lograr un equilibrio fiscal sobre la base de un nivel de recaudación razonable y no solo por vía de reducción del gasto público.

El paradigma de la CEPAL identifica sustantivamente democracia con equidad. La estabilidad democrática dependerá de lo que se avance en los objetivos ligados a la equidad. De aquí se deducen consecuencias muy significativas en el marco de las relaciones laborales.

En primer lugar, con respecto a las relaciones de producción. En la empresa actual, la CEPAL reconoce numerosas metas sistémicas que pasan a ser bienes comunes a empresarios y trabajadores y en torno a las cuales es posible la participación concertada. Así, por ejemplo, en la implementación de sistemas transparentes y equitativos para el relacionamiento de capacitación, productividad e ingresos o salarios, cabría flexibilizar los esquemas de gestión de la empresa, permitiendo a sindicatos y grupos de trabajadores acceso a la información y al procesamiento de propuestas y demandas. Lo mismo vale para el sector público en cuanto organización de servicios.

Pero el énfasis básico de la CEPAL esta puesto también en los procesos reproductivos de la fuerza de trabajo y los actores sociales. De acuerdo a esta lógica, el crecimiento económico estará progresivamente sometido a la evaluación y escrutinio de sus resultados en materia de capacitación y educación, relaciones de género, seguridad del trabajo, oportunidades intergeneracionales, medio ambiente, etc. todas variables relacionadas a los procesos de reproducción de los actores sociales y sus medios sociales y culturales. A este respecto. en el espíritu de la CEPAL cabe promover instituciones que cristalicen propuestas y demandas en torno a estos temas, lo que aumentaría significativamente los niveles de organización y participación concertada de la base social.

La estrategia de la CEPAL se puede estimar como un primer intento por superar una definición restringida de desarrollo social y políticas sociales. Según Raúl Urzúa estos planteamientos estarían alentando la elaboración interdisciplinaria de un paradigma centrado en el redescubrimiento de lo social en cuanto tal, cuestión aún pendiente.

Tras el giro estratégico actual de la CEPAL cabe dejar planteadas algunas preguntas vinculadas a la historia de la institución: a) queda obsoleta la distinción tradicional centroperiferia?, b) con el colapso de las economías socialistas, pierde absolutamente su significado alguna forma de planificación del desarrollo? Finalmente, una cuestión gue estuvo en los circuitos de la CEPAL ¿ ¿se cancela definitivamente la reflexión sobre colonialismo interno y economías de subsistencia?

${ }^{37}$ Raúl Urzúa, "Desarrollo social y reforma del estad", Borrador CAPP. 1994.- 
La fertilidad metodológica de los paradigmas recientemente discutidos se pone a prueba como fuente de orientaciones generales para la construcción de modelos de servicio público.

Como se señalara anteriormente cada uno de los paradigmas discutidos responde a un núcleo de problemas diferenciales y están formulados a diferentes niveles de abstracción. En tanto la Escuela de Opción Pública y la Teoría de Sistema, con distintos énfasis teóricos, quieren proponer alternativas a partir de la crisis del Estado de Bienestar, el paradigma de Igualdad Democrática es un intento en lo fundamental de revitalización de la doctrina liberal. La estrategia de la CEPAL, por su parte, acomete los desafíos que enfrentan los Estados de la región tratando de articular políticamente crecimiento con equidad. A los cuatro esquemas conceptuales, sin embargo, les es común la coordinación de agentes y/o instituciones sociales en el marco de la acción con arreglo a fines. El paradigma de igualdad democrática Rawls) es una doctrina contractualista que como tal supone una ficción hipotética (posición riginal) previa a toda institucionalización y, a diferencia de la escuela de opción pública, la concurrencia de personas morales, libres e iguales.

En un diseño que implique un nuevo pacto social y en congruencia con el diagnóstico obre la matriz de trabajo emergente, la teoría procedimental de Rawls permite realizar el , iguiente experimento imaginario:

Supóngase tres actores principales: sector empresarial y su base social, trabajadores con inserción relativamente estable en el mercado de trabajo, organizaciones o micro-emrresas de baja productividad y centradas en el trabajo. Con independencia de sus diferencias ntemas, los actores saben lo siguiente sobre sí mismos y los otros:

El sector empresarial: i) cuenta con una carta Constitucional que da garantías a la plena -otestad contractual de la propiedad en la empresa; ii) los aumentos de productividad son un equisito funcional para mejorar los niveles de competitividad de la economía en su conjuna: iii) el gobierno le asigna prioridad a una economía competitiva. En consecuencia, el Estado debe asumir temas que contribuyan a aumentar la movilidad de los factores produc○os. Ej. la capacitación profesional y mejorar los expedientes administrativos en relación a i franquicia tributaria.

Los trabajadores: i) por cambio en las reglas del juego institucionales y segmentación Lel mercado de trabajo han perdido fuerza colectiva (baja sindicalización); ii) sus expectatias están deprimidas por los términos de la relación salarial, las condiciones de trabajo y la alidad de los empleos; iii su concurso es fundamental en el funcionamiento de las empresas de la economía nacional; iii) el gobiemo le asigna prioridad a relaciones laborales equita$\because$ as. En consecuencia, exigirán del Estado un rol protector que les permita aumentar su apacidad de negociación sectorial y al interior de las empresas.

Las organizaciones centradas en el trabajo: i) su racionalidad productiva es inconzruente con una economía de mercado; ii) su existencia y estabilidad depende de criterios de - ubsidiaridad o solidaridad; iii) el gobierno le asigna prioridad a la erradicación de la extrema pobreza. En consecuencia, requerirá del Estado asistencia en materia de créditos, capaci:ación técnica, subsidios y transferencias al margen de las instituciones formales. 
Esta situación es potencialmente confrontacional: el Estado enfrentando demandas múltiples y conflictivas de los distintos actores sociales. La atención preferencial a un sector implica conflictos con los otros. Son tendencias que se han observado con ocasión del proyecto de reforma a la legislación laboral actualmente en trámite parlamentario.

Supongamos ahora un velo de ignorancia en que los distintos actores tienen solamente en común "principios destinados a proteger y promover sus sistema de fines", valores de autoestima y autonomía relativa. ¿Qué resultado se tendría al momento de levantar el velo? Los empresarios estarían deseosos que la empresa sea lugar de cooperación sin interferencias políticas y en que predominen relaciones directas con los trabajadores. Los trabajadores anhelan verse organizados con capacidad negociadora y con relaciones respetuosas de sus condiciones de existencia. Las organizaciones centradas en el trabajo con estabilidad y/o sus miembros más jóvenes con sustanciales mejoras en sus posibilidades de inserción en el mercado laboral.

Asumiendo que en una economía de mercado los peor situados son los sectores de baja productividad ¿qué aportes pueden asumir los distintos actores como consecuencia del experimento? Considerando, por una parte, un haz de bienes y valores heterogéneos pero expresivos de los diferentes intereses en juego y, por otra, términos de intercambio razonables (no racionales), ambas condiciones que implica el enfoque de igualdad democrática: los empleadores tendrían que reducir en algunos renglones su potestad contractual, los trabajadores tendrían que aumentar su tecnificación organizacional, las organizaciones peor situadas cambiar sus criterios de racionalidad (rentabilidad).

Al Estado le cabría traducir el consenso institucional generado en la discusión pública reformulando las políticas laborales. ¿Cómo generar transferencias masivas en beneficio de los sectores de más baja productividad? ¿cómo crear o recrear expedientes para ampliar la cobertura de la capacitación profesional? ¿cómo incidir en las normas y la cultura laboral de modo de fortalecer mecanismos de autotutela? etc. serían preguntas pertinentes en este experimento.

Extendiendo y aplicando el experimento a los cuatro paradigmas (presencia y ausencia de condiciones) se obtiene los siguientes criterios de formación de modelos de servicio público:

A. La estrategia del "laissez faire" o paradigma marginalista, en cuyo caso el Estado es externo a las relaciones sociales y solo regulador de las condiciones pactadas en el contrato. Las relaciones laborales desagregadas en términos de mercados de capital y trabajo se resuelven por la vía directa de los activos de poder y el juego de intereses privados.

1. Eje temático:

Empleo, condiciones de trabajo y salarios sometido a leyes de mercado.

2. Temas claves:

i) La empresa privada como eje de la modernización.

Activa política de privatizaciones de patrimonio y activos públicos

ii) Gestión económica. 
Ampliación de libertad de contrato. Desrregulación normativa. Mercado como mecanismo efectivo de distribución económica e integración social.

iii) Lo público y lo privado: la corrupción. público.

Crítica al patrimonialismo del cargo público. Reserva frente a los credos de servicio

B. La estrategia vertical-formal o paradigma sistémico, en donde el Estado como instancia de autoridad normativa fija los límites de las relaciones. Aquí es central la sensibilidad del Estado con respecto a su ambiente y el uso de sus medios de comunicación (inputoutput). Las relaciones laborales se corresponden con un código de normas relativo al mundo del trabajo.

1. Eje temático:

Estado social de derecho y economía de mercado. Congruencia de operaciones.

2. Temas claves:

i) Racionalización de la gestión pública o concepto de eficiencia estatal.

Estructura, tecnologías organizacionales y definición de metas.

ii) Cultura de servicio público.

Contraste entre gestión pública y privada. Servicio al usuario de bienes públicos.

iii) Enfasis en Código del trabajo, Normas y cultura laborales.

C. Las estrategias horizontales, donde cabe distinguir:

C1. La estrategia procedimental o paradigma de igualdad democrática que presume un momento previo a toda institucionalización. Cultura pública informada por los principios de la justicia. Estado responsable del funcionamiento de las instituciones económicas y socia.es. Las instituciones relativas a las relaciones laborales responden a un diálogo entre ciudatanos morales, libres e iguales.

1. Eje temático:

Derechos económicos y sociales del Ciudadano.

2. Temas claves:

i) Justicia distributiva.

Principio de la diferencia y democratización en la evaluación de las políticas póblicas.

ii) Instancias de diálogo social.

Deliberación pública ampliada v's. restringida. Los medios de comunicación y el diáogo social.

iii) Etica del servicio público.

Equidad y recuperación de la dignidad del servicio. 


\section{C2. La estrategia de la democracia sustantiva o de la CEPAL.}

Estado como formulador de políticas integradas y orientadas al crecimiento y la equidad. Como contraparte, importancia de la organización y la participación social concertada. Las relaciones laborales planteadas en dos ámbitos: i a nivel de la organización, flexibilizando los esquemas de gestión; ii a nivel del crecimiento económico, profundizando sus resultados en los procesos reproductivos de los actores sociales.

1. Eje temático:

Integración políticas económicas y sociales.

2. Temas claves:

i) Organizaciones póblicas y privadas y metas sistémicas.

ii) Crecimiento económico y demandas sociales.

Concertación social.

iii) Empiria comparada del servicio público.

Presumiendo que el Gobierno Chileno ha hecho suya la estrategia de la CEPAL, es plausible que a lo menos en el discurso oficial ésta sea la mirada inicial predominante. Cabe esperar que los funcionarios públicos asuman alguna de ellas como mirada preferencial.

\section{MODERNIZACION DEL ESTADO Y RELACIONES LABORALES EN EL GOBIERNO DE LA CONCERTACION.}

\section{Resultados de la Investigación}

Tratándose de una investigación exploratoria a continuación se proponen un conjunto de sugerencias y observaciones de interés para la discusión académica y la formulación de futuras investigaciones.

A modo de hipótesis de trabajo, en el curso de la investigación anticipamos que las distintas fuentes de información no proveen una aproximación unívoca acerca de la modernización del Estado y su significación en términos de relaciones laborales. De hecho, falta de correspondencia conceptual puede observarse en los distintos discursos oficiales y de los funcionarios de la DdT. Por tal razón se exponen unos y otros en forma desagregada.

\section{El Discurso de los Funcionarios ${ }^{38}$.}

Los funcionarios de la DdT se identifican espontáneamente con el sistema público, pero en forma diferencial a otros servicios debido a la particularidad de atender a disputas y compromisos en las relaciones de trabajo. Esta tarea la sienten como una misión o causa de bien público y compatible con un buen nivel de satisfacción laboral, por cuanto implica de una u otra manera al conjunto de la fuerza de trabajo del país. Por el rol fiscalizador que

\footnotetext{
${ }^{38}$ Grupos de Discusión Funcionarios DdT.
} 
ejercen cuentan con nivel de sueldos más aceptables que muchas otras reparticiones estatales, no así en comparación a otros organismos con funciones fiscalizadoras. El criterio de discriminación utilizado entre los servicios de fiscalización es el autofinanciamiento, indicador que mide en términos monetarios el resultado de la gestión. No obstante estas indicaciones, su sistema de retribuciones materiales es un problema de larga data, habiéndose convertido en una de las principales demandas

Coinciden con la percepción pública respecto del bajo rendimiento de la administración estatal. Pero la así llamada 'pobreza franciscana' con que deben realizar sus tareas hace que su desempeño lo estimen como esfuerzos estoicos que priman por sobre los resultados de la gestión. Con respecto a sus capacidades reales de 'resolver problemas' estiman que los resultados son insatisfactorios, al margen de los esfuerzos desplegados. Sienten falta de atribuciones y facultades para incidir en la toma de decisiones. Además, la desvaloración de la experiencia en el servicio por años trabajados conspiran contra un buen rendimiento individual e institucional.

Al régimen militar le imputan la escasa capacidad de negociación y autodefensa que hoy tienen los trabajadores, sean éstos públicos o privados. Hacen referencia a un marco legal y contextual anterior a dicho régimen que parecía atender más al compromiso del Estado y su resguardo del bien común. Opinan desde el derecho y en favor de una reconstucción de la participación negociadora del Estado en materias laborales, cuestión que estiman fuera de sus atribuciones y competencias y poco probable dada la actual dinámica zconómica y la capacidad de presión política del sector empresarial. Consideran su instruinental jurídico poco eficaz para mediar en los conflictos entre trabajadores y empleadores y zoder desde allí modificar el sistema de relaciones laborales. Las reformas en discusión arlamentaria las consideran insuficientes. Parte de las insuficiencias que detectan es que no roceden de una consulta que incorpore la experiencia de quienes constatan en la realidad is bondades y restricciones de la ley. Las dimensiones macro de la política legislativa en $\therefore$ mas laborales es el referente que utilizan para analizar la ineficacia del derecho. Sospezinan de cierta intencionalidad y complicidad en los mandos superiores de gobierno en la mantención de este status.

A las debilidades de la ley como recurso de fallo se suma otras fuentes restrictivas a la :bor del Servicio: i) el desconocimiento de las materias legales por parte de los usuarios, en - p pecial trabajadores y pequeños empresarios; ii) falta de preparación de los funcionarios - ara utilizar la ley como un instrumento ecuánime; y iii) decisiones que deberían adoptar los mcionarios pero que de una u otra forma pueden perjudicar intereses no menores involu-rados en los conflictos.

Las observaciones de los funcionarios en relación a la sociedad civil, las asimetrías ntre empleadores y trabajadores y las insuficiencias del derecho no se vinculan a un discur- relativo a la modernización de las relaciones laborales. La modernización es asociada al opio Servicio. Sin embargo, en esta referencia parece un concepto vago y general. Como xperiencia denota las siguientes dimensiones:

- Discurso institucional progresista;

- Dotación de recursos técnicos y materiales:

- Aumento de la productividad de los funcionarios:

- Capacitación de recursos humanos: 
- Simplificación de procedimientos y concentración de la información;

- Redistribución y reasignación de recursos humanos y materiales.

A diferencia de lo que algunos asocian habitualmente con la modernización estatal y los expedientes de racionalización administrativa, el temor a las exoneraciones no se da entre los funcionarios de la DdT. Temen sí de un proceso de modernización estatal poco reflexivo en que predominen linealmente exigencias de rendimiento y productividad en desmedro de la calidad de atención al público.

Valorizan tareas innovadoras, en particular las fiscalizaciones concertadas, vale decir, visitas a territorios y empresas previamente programadas y conocidas con anticipación por las partes. Pero no visualizan estos procesos inscritos en un esquema coherente y continuo de cambio institucional y teniendo ellos un rol protagónico. Esto conlleva una explícita demanda por ampliar la consulta y la participación.

Las jefaturas parecen tener escasa presencia en las relaciones laborales internas, en el diseño e implementación de políticas pensadas en y para el personal. En la evaluación del rendimiento y la productividad se estaría privilegiando resultados con independencia de escasez de recursos y la cuantificación por sobre la cualificación de lo producido. El funcionario que se desempeña por largo tiempo en un servicio público se volvería menos competitivo, sea por falta de capacitación y/o por no reconocimiento de la carrera funcionaria, cuestiones que muchas veces explican la falta de motivación.

En contraste con su propia autoridad, entre los funcionarios de la DGT prevalece un discurso jurídico-normativo. En términos sistémicos reconocen el derecho como su principal medio de comunicación con el entomo y éste podría ser más eficaz si consagrara mayor simetría en las relaciones de trabajo y el Estado una participación más ejecutiva en la resolución de problemas.

En el marco de restricciones jurídicas y económicas en que trabajan requieren de una capacitación más técnica e integral, que incluya componentes culturales y cuyo centro de gravedad sean las personas. La demanda por mejorar cualitativamente y en contenido la atención al usuario es la principal exigencia al proceso modernizador. Aunque lo formulan en términos muy amplios y genéricos, esta demanda implicaría modificaciones culturales e institucionales de rango mayor, pero por la ausencia de espacios públicos de discusión parecen poco viables.

\section{La Autoridad de la Dirección del Trabajo ${ }^{39}$.}

La Dirección del Trabajo es una institución dependiente del Ministerio del Trabajo y Previsión Social cuya misión fue formalizada en el Decreto con fuerza de Ley $\mathrm{N}^{\circ} 2$, de fecha 29 de Septiembre de 1967. Según la actual administración, esta misión estuvo fuertemente condicionada por el contexto de principio de los años 70: las relaciones laborales se constituyen tripartitamente, con alta explicitación normativa de los mercados de trabajo y activa presencia del Estado en el campo económico y social. El rol básico de la Dirección se especifica en el ámbito de la fiscalización de las condiciones de trabajo con énfasis jurídico y

\footnotetext{
"Dirección del Trabajo, 'Misión Institucional de la Dirección del Trabajo' y 'Metas Consolidadas Dirección del Trabajo'. 1995
} 
preponderantemente punitivo.

En las actuales circunstancias, el Estado estaría abandonando su posición tripartita y desplazándose hacia un bipartidismo. En un marco de modernización y apertura de la economía a los mercados internacionales, al Estado le correspondería fomentar una política de creación de una cultura de respeto a las normas laborales, de participación y confianza en las relaciones de trabajo y de autonomía de los actores sociales.

En esta línea de reflexión, la actual Dirección del Servicio ha definido preliminarmente la misión de éste por 'su contribución a modernizar las relaciones laborales, promoviendo su contractualización sobre la base de la equidad, la autonomía colectiva y el desarrollo de relaciones de equilibrio entre los actores, favoreciendo de tal modo el desarrollo económico del país. Explícita consideración tiene en el Servicio 'la puesta en marcha del gran desafío histórico que es el proceso de modernización del Estado'.

En la Dirección se estima que las regulaciones normativas están relativamente agotadas y ponen especial énfasis en la creación de una nueva cultura organizacional supuestamente válida tanto en el ámbito de la empresa privada como en el servicio público. Esta se traduce en la implementación de dos líneas de acción: por una parte, reemplazar la fiscalización reactiva por la fiscalización programada y, por la otra, incorporar la fiscalización concertada, pues, independiente de la cantidad de multas, lo que interesa en última instancia es el impacto de la acción del Servicio en las relaciones laborales. El funcionario sería visto como un recurso que puede paulatinamente convertirse en agente portador del cambio en las relaciones de trabajo, lo cual pasa por invitar a la participación y delegar niveles de responsabilidad. Se reconoce en la Dirección que en esta materia falta mucho por hacer.

La optimización de recursos disponibles va por el lado de la reformulación de procesos $\checkmark$ la combinación de parámetros de evaluación tanto cuantitativos como cualitativos. Entre otras, incluyen una serie de innovaciones tendientes a mejorar la calidad de atención a los usuarios, las cuales constituyen metas específicas de modernización.

Entre las innovaciones registradas se cuentan el Plan Piloto de Inspecciones Estratégicas, orientado a acelerar el tiempo de reacción del Servicio en los procedimientos de comparendos y fiscalizaciones; de aquí se espera la generación de un sistema de indicadores de gestión. Durante el año 1995 se creó un servicio de consulta telefónica al usuario sobre dudas acerca de la legislación laboral; tiene cobertura nacional y se estima un máximo de consulta de 28.000 llamadas anuales. Se están mejorando las bases de datos de la Dirección con respecto a la validez, confiabilidad y actualización de la información: ecte esfuerzo deberá redundar en un menor tiempo empleado en los procesos de registro en las inspecciones comunales, estimando un ahorro de 14.000 horas-hombre anual. Se contempla también una ampliación de la cobertura por la vía de la creación de un sistema de fiscalización itinerante. Finalmente, la Dirección se propuso desarrollar un ejercicio de desarrollo institucional, asistido externamente, el cual defina el marco de desarrollo estratégico de la organización en el mediano y largo plazo; ligado a este ejercicio se creó una unidad de Planificación Estratégica y se ha definido una orgánica de funcionamiento, donde se distinguen niveles estratégicos, tácticos y operativos.

En términos administrativos se ha puesto énfasis en dos aspectos muy importantes en 
una institución con roles de fiscalización: por una parte, el incremento de los controles internos con vistas a aumentar la transparencia, bajo el concepto de 'probidad funcionaria'; por la otra, la intensificación de la capacitación a los niveles más ejecutivos entre fiscalizadores y técnicos y planes de formación en Gestión y Administración por Objetivos para jefes operativos en regiones.

En suma, entre las autoridades de la DGT se manejan simultáneamente dos conceptos de modernización. El primero, referido a la modernización de las relaciones laborales, focalizada en términos sistémicos no a los nexos jurídico-normativos sino que a la cultura organizacional. Este concepto se entiende de preferencia a la relación bipartita entre trabajadores y empleadores del sector privado. El segundo, referido a las instituciones póblicas y que se traduce en mejora cualitativa y cuantitativa de la gestión y la atención a los usuarios del Servicio. Los avances en la cultura organizacional del propio Servicio han sido menores, lo que se explica en parte por la larga experiencia del régimen autoritario y la vigencia de un organigrama de funcionamiento eminentemente verticalista y jerárquico.

\section{El Gobierno de la Concertación.}

En el documento 'Principios Orientadores de Modemización de la Gestión Pública' se afirma que tres procesos impulsan la modernización del Estado Chileno. En primer lugar, el agotamiento del Estado interventor y la transición a una forma de Estado distinta. En segundo lugar, el tránsito que se observa desde una cultura de súbditos a una cultura de ciudadanos. En tercer lugar, la creciente percepción de desincronizaciones y déficits en la relación entre la gente -o 'principal' del Estado- y el funcionario y la clase política profesional -o 'agente' de ese principal- ${ }^{40}$.

El propósito del gobierno durante el sexenio (1994-1999) será impulsar un proceso que lleve a que el conjunto de las actividades póblicas se oriente por la obtención eficaz y eficiente de los resultados que su misión le exige producir. (Así), el sentido más primordial y más profundo de la política de modernización estatal será transitar gradual y sostenidamente hacia un estilo de gestión estatal y gubernamental orientada por resultados.

Con estos principios orientadores, el Gobierno impulsa desde la Dirección de Presupuesto el 'Plan Piloto de Modernización de la Gestión en Servicios Públicos'. En la discusión presupuestaria para 1995, este Plan acompañó indicadores y metas de desempeño en 26 servicios públicos ${ }^{41}$.

Los indicadores de desempeño se pueden clasificar en cuatro grandes categorías:

1. Indicadores de cobertura: identifican el número de usuarios atendidos o prestaciones entregadas.

2. Indicadores de oportunidad servicio: miden la rapidez de respuesta o tiempo requerido para entregar un determinado servicio al usuario.

\footnotetext{
to Comité Interministerial, op. cit.

${ }^{4}$ Ministerio de Hacienda. 'Plan Piloto de Modernización de los Servicios Públicos'. 1995.
} 
3. Indicadores de eficiencia: miden la relación entre productos o servicios e insumos.

4. Indicadores de autofinanciamiento: miden la capacidad de los programas de generar sus propios recursos para financiar su actividad, reduciendo su dependencia de los aportes provenientes de fondos generales de la nación.

Las Orientaciones y su implementación en el Plan parecieran en principio alinear la postura de gobierno sobre la modernización del Estado al paradigma de Opción Pública. la cual no establece distinción alguna entre los bienes públicos y los bienes privados, definidos los primeros por 'su condición de indivisibles, no exclusivos y de consumo conjunto' y mediados por los derechos del ciudadano. Esta ausencia de distinción permitiría una transferencia directa de los procedimientos habituales de la administración privada al sector público. Sin embargo, cabe señalar alguna distancia del gobierno de dicho paradigma y ésta es preciso buscarla en sus componentes cepalino y sistémico.

En efecto, de la estrategia de la CEPAL, el Ministro Arrate asume "la ecuación de crecimiento con equidad. A este respecto señala que el crecimiento económico es sin duda condición necesaria de cualquier avance significativo en el plano de la justicia social. Pero en un país como Chile con un nivel cultural relativamente alto, con larga tradición pública de sentido social y con un movimiento sindical de larga data, la equidad es condición sine qua non del crecimiento"4?.

También del paradigma de la CEPAL se asumen criterios relativos a demandas al crecimiento económico, vale decir, someter sus resultados a los procesos reproductivos de los actores y sus medios sociales y culturales. Campero es explícito en esta cuestión, al sostener que es preciso "identificar el momento en que la retención inflacionaria ceda el paso a algún margen mayor de flexibilidad para invertir más socialmente en salud, educación y seguridad social"4.

En un plano más metodológico se puede inventariar los componentes sistémicos:

1. De la economía social de mercado se señalan cuestiones prioritarias como insumos del sistema político y el Estado. En términos del Ministro Arrate "es preciso: i) situar el tema de la productividad y su incremento como cuestión central; ii) enfrentar con criterio de anticipación los impactos de reconversión productiva y iii propender a que la creciente integración comercial de Chile con otros países signifique beneficios socialmente compartidos" $"$. En otro plano, Campero enfatiza "lo que corresponde ahora es abrirse a los temas realmente de futuro, esto es, seguro de desempleo, capacitación y formación profesional. innovación tecnológica, institucionalidad pública para la integración subregional y de libre comercio, en definitiva modernización macro social"... "Sobre esa base será más probable abordar los nuevos temas en un marco de relaciones laborales mejor construidas en la empresa"45.

2. Para la tarea señalada se afirma al derecho y la economía como medios comunicativos y obnivalentes fundamentales. En palabras del Ministro. " derecho y economía se deben

\footnotetext{
+2 Jorge Arrate Mc N. 'Modernización. Equidad y Relacioncs Luhorales Participativas'. Noviembre 1994.

${ }^{43}$ Entrevista ref.

$\because$ Arrate, op. cil.

${ }^{45}$ Arrate, op cit.
} 
combinar para construir equilibrios en las tres grandes cuestiones antes señaladas". Sin embargo, a renglón seguido, el Ministro advierte sobre las restricciones de ambos instrumentos. "No es acertado confiar los esfuerzos protectores del trabajo solo a la eficacia de la tutela estatal y creer que el derecho es suficiente para conseguirla. Tampoco es acertado privilegiar las condiciones de flexibilidad económica que pudieran fortalecer las posibilidades de crecimiento buscando desregulaciones que, inequívocamente. conducen a la desprotección de sectores y a inequidades sociales mayores" 46 . En el tenor de otros discursos se presume que los arreglos puramente jurídico-normativos están relativamente agotados. Esto último sería válido tanto con respecto a las normas laborales (Campero) como en relación a las regulaciones entre Estado y economía (Mejías). Como se ha anotado y desde otra perspectiva entre los funcionarios de la DGT se confirma también la poca eficacia del Derecho.

3. Se perfilan roles diferenciados del gobierno, el sistema político y de los actores sociales. El gobiemo afirma su autonomía en torno a una política de Estado y reconoce el carácter estratégico de los actores en la medida que se alinien a esa política. Según Campero esto "supone abandonar todo imaginario populista, clasista o corporativista para examinar adecuadamente el rol gubernamental"47. Como contraparte, el gobierno favorece la autonomía de los actores propugnando el tránsito de la tutela administrativa a la autotutela. La mayor coherencia en el discurso del gobiemo y de las autoridades de la DdT esta referido precisamente a la demanda de autonomía de los actores sociales. A diferencia de la postura neoliberal individualista aquí se trataría de actores organizados que, sin suprimir tensiones legítimas, son capaces de construir "grandes acuerdos que generen áreas de interés común".

4. Las relaciones laborales son percibidas como punto sinérgico crítico. El cambio en éstas se estaría dando en un modelo de suma positiva. Sobre la base de lograr progresos sustanciales en el desarrollo de mejores relaciones laborales, los frutos generados en los procesos productivos pueden beneficiar tanto a trabajadores como empleadores y, por cierto, a la sociedad en general. Este proceso se entendería en forma desagregada y no estaría mediado por el Estado ni el sistema político, "en la medida que las relaciones laborales son hoy relaciones radicadas en la empresa, más tecnificadas y económicas" (Campero). Esta nueva situación politiza de otra manera a las relaciones laborales: "hace a los actores sociales tipo CUT o CPC corresponsables de pactar las reglas de estabilidad global del sistema, pero no les otorga capacidad para intervenir en la fijación de las condiciones de trabajo y empleo al nivel microeconómico" (Campero). El Estado debe resistirse a estas tendencias corporativas de las organizaciones del mundo laboral, "aunque el gobierno sabe que (en sus esfuerzos por mantener una política de Estado) estará siempre al medio de tensiones con uno y otro actor y con sectores de los partidos políticos" (Campero).

En suma, entre las autoridades superiores de gobierno se presume un sistema económico estructurado en sus comunicaciones: economía de mercado, mercado de trabajo, homo economicus, etc. En este contexto al Estado le cabe pactar con los actores sociales tipo CUT y CPC y hacerlos corresponsables de las reglas de estabilidad global del sistema económico. Su código debe estar más orientado por las variables técnico-económicas que por cuestiones jurídico-normativas. En términos de su estructura interna y procedimientos el Estado debe considerar como prioridad "el mejoramiento de las relaciones de trabajo y la apertura formal y articulada de instancias de participación y diálogo".

\footnotetext{
th Arrate op cil
}

${ }^{47}$ Entrevista ref. 
En la teforma y reestructuración del Estado pareciera darse una antinomia entre el modelo de planificación estratégica que inspira el accionar del gobierno y el ethos tradicional del servicio público, antinomia que por cierto se hace mas ostensible a medida que se desciende en la jerarquía institucional. Formulado en términos esquemáticos, en tanto el modelo del gobierno apunta a:

- Alta movilidad de recursos humanos y criterios de flexibilidad laboral;

- Indicadores de gestión eminentemente cuantitativos;

- Alta asociación entre productividad y remuneraciones; y

- Capacitación orientada por misión y resultados del servicio público.

El ethos de servicio público tiene un perfil con énfasis en:

- Patrimonialismo del cargo público (inamovilidad);

- Vocación de servicio con independencia de resultados;

- Alta valoración de la experiencia o antigüedad en el servicio; e

- Importancia de los procedimientos con arreglo a la forma (derecho)

En los modelos de acción estratégicos los funcionarios sienten que pasan a ser objeto de la modernización y "tienden a identificar problemas que imputan a otros y soluciones que no dependen de ellos'48. El ethos de servicio público, por el contrario, se expresa hoy con demandas de mayor participación y protagonismo en el proceso. Esta última es la postura consensuada entre los funcionarios de la DdelT.

En caso de confirmarse esta hipótesis cabe presumir una fuerte distancia y disociación entre la voluntad y decisión política de modernización estatal y la disposición o capacidad de recepción de la burocracia pública. Los recientes conflictos en los sectores de la educación y la salud pública parecen ser expresivos del fenómeno a que se hace referencia.

Sería de sumo interés diseñar modelos de capacitación y gestión que sean más convergentes con los propósitos esbozados por las distintas fuentes de información. Hipotéticamente el concepto de cultura organizacional propuesto por la Dirección del Trabajo podría proveer un enfoque mediador y articulador entre ambos aprontes al servicio público. Este tema, por cierto, excede los alcances de esta investigación.

\section{Comentarios finales.}

Volviendo en términos más generales al marco analítico, se puede señalar que el gobierno de la Concertación pareciera estar asumiendo un enfoque ortodoxo de la modernización. Su visión de la sociedad civil y las relaciones de ésta con el Estado es de carácter institucionalizado y sistémico y tiende a privilegiar a los actores organizados. Las relaciones laborales se visualizan en términos contractuales entre entidades colectivas y autónomas o en procesos de autonomización. La progresión hacia relaciones bipartita entre empleadores y trabajadores es concebida de preferencia en el marco de la empresa como relaciones técnico-

tA Angel Flisfisch, Diario La Epoca Febrero 5.1995 "El difícil camino hacia la Modernización del Estado". 
económicas. La modernización del Estado pasa a ser así una cuestión de aumento de la eficacia y eficiencia al servicio de la gente; en este contexto la noción "gente" connota más la idea de "cliente" que de "ciudadano". Los funcionarios de la Dirección General del Trabajo, por el contrario, perciben más asimetría que autonomía y reivindican en general una mayor y más potente ingerencia del Estado en las relaciones laborales.

A nivel de las autoridades superiores de gobierno, en consecuencia, la puesta al día de la democracia atingente a este proceso de modernización se puede entender en términos sistémicos como una puesta al día de su propio código, con especial y casi exclusiva referencia a la transición política y la transnacionalización económica. Las cuestiones enfatizadas por el paradigma de igualdad democrática y relativas al nuevo status de la ciudadanía emergen intuitivamente como una aspiración poco viable de funcionarios de rango menor y al parecer quedan como temas independientes del Estado y asuntos del propio ciudadano.

En el próximo quinquenio el sector empresarial puede "estar tranquilo y sin nervios"(*). Al lugar protagónico en la economía social de mercado, en especial en los procesos de transnacionalización de la economía, el Estado chileno está reconociendo para sí explícitamente el modelo de racionalidad del "homo economicus" en a lo menos dos aspectos muy fundamentales. En primer lugar, en los modelos de gestión empresarial o administración por resultados, donde el Estado asume una condición de empresa de servicios y "la gente" es visualizada como usuario de servicios públicos.

En segundo lugar, en cuanto la modernización del Estado es vista en términos de relaciones de trabajo como el tránsito de un sistema de adhesión administrativa a un sistema contractual de tipo privado. Esto sería congruente con implantar la negociación colectiva sin inamovilidad y con el despliegue de indicadores y metas de desempeño de uso habitual en la administración privada,

Paradojalmente lo que estaría bloqueando al sector empresarial es su adhesión irrestricta a un concepto ideológico de absoluta potestad contractual en la empresa. Esto se expresa en el discurso de los funcionarios de la DGT en la constatación de una relación asimétrica y autoritaria donde, en especial en la Pequeña y Mediana empresa, los trabajadores en muchas ocasiones no están en condiciones de pactar ni siquiera los términos de su propio contrato.

Finalmente, cabe anotar que esta investigación permitió explorar un conjunto de aspectos de alta significación político institucionales. Como tema pendiente para futuras investigaciones pareciera pertinente continuar indagando en términos empíricos acerca de las condiciones que facilitan o no la transferencia de modelos de gestión entre los sectores público y privado. Esta es una materia altamente sesgada en la discusión por cuestiones ideológicas y donde las posturas neoliberales han ganado terreno en amplios espacios de la opinión pública. Las investigaciones que se sugieren podrían proveer de mayor realismo a las políticas de modernización del Estado.

Expresión coloquial venezolana. 


\section{BIBLIOGRAFIA GENERAL.}

- Alburquerque. Mario \& G. Jiménez "Actores sociales más allá de la transición” 1988.

- Arendt, Hannah "La condición humana" Paidós, 1993.

- Arrau, Alfonso "Modernización y redemocratización en Chile" en R.S. U de Ch. 1992

- Atria, Raúl \& Matías Tagle Ed. "Estado y Política en Chile CPU 1991.

- Berman, Marshall "Todo lo sólido se desvanece en el aire" Siglo XXI Ed. 1988.

- Boulding, Kenneth E. "Las tres caras del poder" Paidós, 1993.

- Boeninger, Edgardo \& E. Correa "Transición a la democracia. Marco político y económico, en Cieplan 1990.

- Buchanan J.M. "The limits of Liberty" Chicago University Press, 1975.

- Buchanan J.M. \& G. Tullock "The calculus of consent" Ann Arbor, Michigan Press 1962.

- Calderón, Fernando y Dos Santos "Hacia un nuevo orden estatal en América Latina".

- Castañeda, Tarciso "Para combatir la pobreza". CEP 1992.

- Campero, G.. A. Flisfisch, E. Tironi, V. Tokman "Los actores sociales en el nuevo orden laboral" Ed. Dolmen OIT 1993.

- Cavarozzi, M. "Más allá de la transición" Rev. Estudios Políticos N 74.

- CEPAL-CELADE "Transformación ocupacional y crisis social en América Latina, 1989.

- CEPAL-CELADE "Transformación productiva con equidad”, 1990.

- CEPAL-CELADE "La equidad en el panorama social de América Latina", 1991.

- CEPAL-CELADE "Equidad y transformación productiva", 1992.

- CEPAL-UNESCO "Educación y conocimiento: Eje de la transformación productiva 1992

- CEPAL-CELADE "Población. equidad y transformación productiva". 1993.

- CLACSO 1991 "Hacia un nuevo orden estatal en América Latina" 6 vol.

- Cortázar, René "Política laboral en Chile democrático"

- Crossman, R.H.S. "Biografia del Estado moderno" FCE. 1986.

- Dahl, Robert "La democracia y sus críticos" Paidós 1991.

- De la Cruz, Rafael "Descentralización, gobernabilidad, democracia" CPU 1992.

- Drake \& Jacsic "La batalla por la democracia" Ed. Flacso 1983.

- Espinoza, Vicente "Un sistema autoritario de gestión de servicios" Sur No 127.

- Estudios Públicos IV-V "Moral y mercado" CEP.

- Eugenin, Jorge y otros "Regionalización, la experiencia chilena 1974-1989", U. de Ch.

- Flacso, "Chile: 1973-198?" Flacso 1983

- Flisfisch, Angel "La política como compromiso democrático" Flacso.

- Flisfisch, A. \& J. Irarrázaval "El futuro democrático de Chile". U, de Ch.

- Foro 90 "Modernización del Estado y consolidación democrática en Chile, 1992.

- Foro 90 "Estado y seguridad ciudadana", 1992.

- Foro 90 "Estado y desarrollo", 1992.

- Foro 90 "Estado y actores sociales, 1993.

- Foxley, Alejandro "Chile y su futuro. Un país posible" Ed. Cieplan 1988.

- Foxley, Alejandro "La economía política de la transición" 1993.

- Freund, Jullien "La crisis del Estado y otros estudios" U. de Ch.

- García. Alvaro "Las orientaciones de la política social" Cieplan No 31, 1991.

- García. Eduardo "El papel del Estado en la producción" CED 1986.

- García Pelayo, Manuel "Las transformaciones del Estado contemporáneo" A.U. 1992.

- Garretón, Manuel A. "El aprendizaje político en la redemocratización" E. P. 1992.

- Garretón M.A. \& Malva Espinosa "Reforma del Estado o cambio en la matriz socio-política". Ponencia al IV Congreso chileno de sociologia, 1992.

Giddens. Anthony "The consequences of modernity" Stanford 1990.

- Giddens, A. "La estructura de clases en las sociedades avanzadas" A.E., 1979.

- Góngora, Mario "Ensayo histórico sobre la noción del Estado en Chile E.U. 1981.

- Habermas, Jürgen "Teoría de la acción comunicativa" 2 tomos Tauros Ed. 1990.

- Habermas, Jürgen "Escritos sobre moralidad y eticidad" Paidós 1991.

- Hachette, D \& R. Luders "La privatización en Chile" CID 1992

- Hansen. J. M. "The political economy of group membership" A.P.Sc.R. 791985.

- Heller, Hermann "Teoría del Estado", FCE, 1992.

- Huntington, Samuel P. "El orden político en las sociedades en cambio" Paidós 1990.

- Ibáñez. Jesús, "Más allá de la Sociología. Teoría y Práctica del grupo de discusioonn, Ed. Siglo XXI. Madrid 1979.

- Irarrázaval, Ignacio Ed. "Desafíos de la descentralización" CEP 1993.

- Johansen, O., R. de la Cuadra, V. García, "Hacia una teoría de la Organización", 1992.

- Keane, John "Public Life \& Late Capitalism"

- Kingdom. John "Agendas, alternatives and public policies" Boston 1984.

- Krueger, A. "El Grupo de Discusión. Guía práctica para la investigación aplicada“ Ed. Pirámide, Madrid 1991.

- Lahera Eduardo Ed. "Cómo mejorar la gestión pública" Cieplan-Flacso-Foro 90, 1993.

- Larraín, Felipe Ed. "Chile hacia el 2000" CEP, 1994.

- Larrañaga, Osvaldo "Política social en Chile 90-93" Ilades, 1992. 
- Lechner, Norbert "El debate sobre estado y mercado" Flacso, 1992.

- Lechner, Norbert "Reflexiones acerca del estado democrático" E.P. 1992.

- Luhmann, Niklas "El sistema social"

- Luhmann, Niklas "La teoría política del estado de bienestar" A.U. 1993.

- Mann, Michael "The autonomous power of the state" Archives Europeenes 1984.

- Marcel, Mario "La privatización de empresas públicas en Chile" Cieplan 125, 1989.

- Meller. Patricio y Otros "Los gobiernos de Aylwin y Pinochet" Cieplan 118, 1993.

- Muñoz, Oscar Ed. "El rol del Estado en América Latina" Doc. 1990.

- Muñoz. Oscar "Después de las privatizaciones hacia el estado regulador" Cieplan 1993.

- North, Douglass "Qué queremos decir cuando hablamos de racionalidad" E.P. 1994.

- O'Donell "Democracia delegativa? Cuadernos de CLAEH, 1992.

- Olson, M. Jr. "The rise and decline of nations" Yale U. Press, 1982.

- Osborne David \& Gaebler T. "La reinvención del gobierno" Paidós, 1994.

- Paredes. Ricardo "Hacia un estado regulador" Cieplan, 1993.

- Polanyi, Karl "La gran transformación" FCE. 1992.

- Przeworski, Adam "Capitalismo y socialdemocracia" Alianza Ed. 1990.

- Rawls, John "Teoría de la justicia" FCE, 1993.

- Rawls, John "La justicia como equidad"

- Reueschemeyer, Dietrich y Otros "Capitalist development \& democracy" Chicago, 1992.

- Revista del CLAD "Reforma y democracia" Nro. 2, 1994.

- Riker. W.H. \& Ordeshook P.C. "Theory of the calculus voting" A.P.Sc.R. 1968.

- Rosenfeld. Alcjandro "Estado, descentralización municipal y gestión económica“ Sur.

- Slater 1985 "New social movement and the state in Latin America" Foris Pub. Holland.

- Stigler. G.J. "The theory of economic regulation" Ch.S.P.E., U. of Chicago, 1988.

- Tagle. Matías Ed. "Desafíos del estado en los años 90" CPU.

- Tironi. Ernesto "Otro rol para el estado de Chile" CED. 1987.

- Tironi, E. "Autoritarismo, modernización y marginalidad" Ed. sur, 1989

- Tomassini, Luciano "La reforma del estado y las políticas públicas" CAPP, 1994.

- Touraine. Alain "Crítica de la modernidad" FCE. 1994.

- Touraine. Alain "Política y sociedad en América Latina" Espasa Calpe, 1989.

- Urzúa. Raúl "Desarrollo social y reforma del estado" CAPP (borrador)

- Walker. Francisco \& Arrau A. Ed. "Las relaciones de trabajo en el Chile de hoy", 1993.

- Weffort. Francisco "Qual democracia" Sao Paulo, 1992.

- Zapata. Francisco comp. "Clases sociales y acción obrera en Chile“ ECM, 1986. 